\title{
Response to Hypoxic Preconditioning of Glial Cells from the Roof of the Fourth Ventricle
}

\author{
Marymar Becerra-González, ${ }^{a}$ Ragu Varman Durairaj, ${ }^{a}$ Aline Ostos Valverde, ${ }^{a}$ Emilio J. Gualda, ${ }^{b}$ Pablo Loza-Alvarez, ${ }^{b}$ \\ Wendy Portillo Martínez, ${ }^{\mathrm{C}}$ Gabriela Berenice Gómez-González, ${ }^{\mathrm{a}}$ Annalisa Buffo ${ }^{\mathrm{d}}$ and Ataúlfo Martínez-Torres ${ }^{\mathrm{a} *}$ \\ a Instituto de Neurobiología, Departamento de Neurobiología Celular y Molecular, Laboratorio de Neurobiología Molecular y Celular, \\ Universidad Nacional Autónoma de México, Juriquilla, Querétaro 76230, Mexico \\ ${ }^{\mathrm{b}}$ ICFO-Institut de Ciencies Fotoniques, The Barcelona Institute of Science and Technology, Av. Carl Friedrich Gauss, 3, 08860 \\ Castelldefels (Barcelona), Spain \\ ${ }^{\mathrm{c}}$ Instituto de Neurobiología, Departamento de Neurobiología Conductual y Cognitiva, Laboratorio de Plasticidad y Conducta Sexual, \\ Universidad Nacional Autónoma de México, Juriquilla, Querétaro 76230, Mexico \\ ${ }^{\mathrm{d}}$ Department of Neuroscience Rita Levi-Montalcini, University of Turin, Neuroscience Institute Cavalieri Ottolenghi (NICO), 10043 \\ Orbassano, Torino, Italy
}

\begin{abstract}
The cerebellum harbors a specialized area on the roof of the fourth ventricle that is composed of glial cells and neurons that interface with the cerebrospinal fluid. This region includes the so-called ventromedial cord (VMC), which is composed of cells that are glial fibrillary acidic protein (GFAP)-positive and nestin-positive and distributes along the midline in association with blood vessels. We hypothesized that these cells should compare to GFAP and nestin-positive cells that are known to exist in other areas of the brain, which undergo proliferation and differentiation under hypoxic conditions. Thus, we tested whether cells of the VMC would display a similar reaction to hypoxic preconditioning (HPC). Indeed, we found that the VMC does respond to HPC by reorganizing its cellular components before it gradually returns to its basal state after about a week. This response we documented by monitoring global changes in the expression of GFAP-EGFP in transgenic mice, using light-sheet fluorescence microscopy (LSFM) revealed a dramatic loss of EGFP upon HPC, and was paralleled by retraction of Bergmann glial cell processes. This EGFP loss was supported by western blot analysis, which also showed a loss in the astrocyte-markers GFAP and ALDH1L1. On the other hand, other cell-markers appeared to be upregulated in the blots (including nestin, NeuN, and Iba1). Finally, we found that HPC does not remarkably affect the incorporation of BrdU into cells on the cerebellum, but strongly augments BrdU incorporation into periventricular cells on the floor of the fourth ventricle over the adjacent medulla. This article is part of a Special Issue entitled: Honoring Ricardo Miledi - outstanding neuroscientist of XX-XXI centuries. () 2019 IBRO. Published by Elsevier Ltd. All rights reserved.
\end{abstract}

Key words: Bergmann glia, cerebellum, clarity, light sheet fluorescence microscopy, microglia, hypoxia.

\section{INTRODUCTION}

The mammalian cerebellar cortex is composed of three layers of cells that are regularly distributed, in the same pattern throughout all ten of its lobules. In all, the somata of Purkinje neurons and Bergmann glial (BG) cells occupy the so-called Purkinje cell layer, located between the outermost molecular layer (formed by basket and stellate neurons) and the innermost granular

\footnotetext{
*Corresponding author.

E-mail address: ataulfo@unam.mx (A. Martínez-Torres).

Abbreviations: BG, Bergmann glia; CSF, cerebrospinal fluid; EGFP, enhanced green fluorescent protein; GFAP, glial fibrillary acidic protein; HPC, hypoxic preconditioning; LSFM, light sheet fluorescence microscopy; ROI, region of interest; SVZ, subventricular zone; VMC, ventromedial cord.
}

layer (formed by granule and Golgi neurons) (Hoogland et al., 2015; Hibi et al., 2017). The functional organization of the cerebellum is modular, i.e., determined by connections with other brain areas in a zone-specific manner, which has been clearly elucidated (Voogd and Glickstein, 1998; Witter and De Zeeuw, 2015). However, the relationships of cerebellar lobules with the central ventricular system of the brain are variable, because lobules III-VII face the subarachnoid space, while lobules I, II and $X$ face the fourth ventricle. This gives rise to a situation in which ciliated ependymal cells cover the surfaces of the latter lobules and bathe in cerebrospinal fluid (CSF).

Our recent observations on lobules I, II and X on the roof of the fourth ventricle have shown cellular diversity amongst the ependymal cells that contact the CSF as well as the cells that are located just under them, in 
what is known as the subventricular zone (SVZ). Using patch-clamp electrophysiology and immunofluorescence microscopy, we have shown that within the SVZ reside astroglial cells, oligodendrocytes, neurons, and possibly even glial or neuronal progenitor cells (González-Gonzá lez et al., 2017, Reyes-Haro et al., 2013). Therefore, the organization of this area contrasts dramatically with the homogeneous cytoarchitecture found in the rest of the lobules of the cerebellum, and represents a unique environment in which CSF, blood vessels, and brain parenchyma all converge. Here, in the SVZ, the cells that form the wall of the ventricle are in a strategic position to sense changes in the CSF, which is known to play important roles in signal transduction and to transport hormones and other chemical signals throughout the brain, all parts of maintaining homeostatic control (Del, 1995; Cipolla, 2009; Zhang et al., 2015).

Additionally, on the very roof of the fourth ventricle exists a unique population of ependymal cells that differ from all the rest by being only biciliate, and by extending in a streak-like fashion along the midline (González-Gon zález et al., 2017). These we call the ventromedial cord (VMC), which we find also includes certain GFAP + and nestin + cells (usually taken as identifying neural stem cells), which have a single process that projects towards the interior of the cerebellum.

Similarly, neuronal progenitor cells in the adult hippocampus display prominent extensions throughout the granular cell layer and, unlike other glial cells within the area, express nestin as well as GFAP in their intermediate filaments (Kriegstein and Alvarez-Buylla, 2009). Such neuronal progenitor cells are found under normal conditions and may be activated after injury in several regions of the adult nervous system, including the spinal cord, the SVZ of the lateral ventricles, and the subgranular zone of the hippocampus (Lang et al., 2015). In the latter region, these neuronal progenitor cells resemble classical glial cells, in that they express nestin and GFAP, and they proliferate and differentiate under HPC a stereotyped method of temporary, mild oxygen deprivation that does not induce any irreversible cellular damage, but is widely employed and studied, due to its neuroprotective and plastic effects (Santilli et al., 2010; Lang et al., 2015).

Many types of mild noxious stimuli are effective in conferring this sort of protection to a range of tissue types (including the brain) as part of the innate tolerance in various organisms. These non-lethal stimuli include temporary ischemia, hyperthermia, physical exercise, lipopolysaccharide, glutamate, and most especially, the use of mild hypoxia (HPC), which has been used repeatedly and successfully to reduce injury from a subsequent serious ischemic insult to the brain (Gidday et al., 2013). Abundant evidence has been presented for neuronal plasticity and repair in response to $\mathrm{HPC}$, in areas of the brain as diverse as the spinal cord and the cerebral cortex, with clear cut indications that parenchymal cellular neogenesis is involved in this repair (Bonfanti, 2013). Less well documented, however, is whether or not the same sort of cell proliferation occurs in the cerebellum in response to HPC - anything like which occurs in the cortex in response to HPC - and if so, whether this response is significant, compared to the original cellular proliferation that occurs during cerebellar development (Ponti et al., 2008; Feliciano et al., 2015; Ahlfeld et al., 2017; Mandalos et al., 2018).

Thus, we sought in this study to determine whether the GFAP + cells that form the VMC respond to HPC, and how they respond. Additionally, we sought to determine the impact of HPC on the nearby BG cells in the cerebellum. Here, we focused on BG cells because it is well known that during cerebellar development, these cells provide essential scaffolds for the migration and layering of granular neurons (De Zeeuw and Hoogland, 2015). Additionally, such BG cells surround Purkinje neurons and remain critically important throughout adult life (as has been shown by genetically ablating their AMPA receptors and achieving a severe impairment in motor coordination) (Saab et al., 2012). However, even though BG cells in the region extend their processes towards the fourth ventricle, they do not contact the cells in the VMC directly. Instead, their end-feet are covered with a limiting basal membrane (González-González et al., 2017). Consequently, we felt it was important to determine whether BG cells would respond to HPC, and if so, if their response was anything like that of GFAP + cells in the VMC.

To evaluate this, we applied a combination of techniques, including immunofluorescence, CLARITY, LSFM and BrdU incorporation - all to assess whether or not cell proliferation occurred in the VMC (and in Bergman glial cells) in response to HPC.

\section{EXPERIMENTAL PROCEDURES}

\section{Ethical statement}

All procedures on mice were carried out in accordance with the regulations of the Society for Neuroscience: Policies on the Use of Animals and Humans in Neuroscience Research and on local and international bioethical guidelines including the NOM-062-ZOO, which is in accordance with the recommendations of the National Institutes of Health publication titled "Guide for the Care and Use of Laboratory Animals" (National Research Council (U.S.). Committee for the Update of the Guide for the Care and Use of Laboratory Animals. And Institute for Laboratory Animal Research (U.S.), 2011).

\section{Animals}

Postnatal 26 (P26) male mice (CD1, GFAP-EGFP and Pax2-GFP mice) bred at the animal facility of the Instituto de Neurobiología UNAM, Juriquilla, Querétaro or at the University of Turin were selected and kept under a controlled $12 \mathrm{~h}$ light $/ 12 \mathrm{~h}$ dark cycle at 20 $\pm 1^{\circ} \mathrm{C}$. Mice expressing EGFP under the human GFAP promoter (Nolte et al., 2001) were kindly donated by Prof. Helmut Kettenmann (Max Delbrück Center, Berlin). This transgenic mouse strain was selected for brain clarification since EGFP is strongly expressed in the cerebellum. Water and food ad libitum were provided, and cages were replaced ad lib to maintain cleanliness and dryness. 


\section{Hypoxic preconditioning}

Following the protocols used in earlier reports, HPC was produced by placing mice inside $50 \mathrm{ml}$ conical tubes and sealing the caps tightly (Zhang et al., 2011; Liu et al., 2012; López-Aguilera et al., 2012; Benitez et al., 2014). As soon as the mice started gasping, they were removed from the tubes. This we considered to be one cycle of HPC, and this we repeated three times on every mouse, with $15 \mathrm{~min}$ of recovery in normal oxygen in-between each cycle. This form of 'auto-hypoxia' is thus produced by the animal's own oxygen consumption and is one of the earliest methods of HPC (Rybnikova and Samoilov, 2015).

Not surprisingly, the mice's ability to tolerate anoxia became longer and longer with each successive trial, the average time of runs 1,2 and 3 being $201 \pm 22.15$, $350 \pm 39.16$, and $573 \pm 64.83 \quad$ (seconds \pm SE, respectively). Fig. 1 shows the hypoxia tolerance-time of all the mice exposed to HPC. In other words, the protocol for HPC used here induces immediate tolerance and protection to anoxia, as was documented in Li et al. (2017).

To make sure that this approach to HPC was not inducing some other form of stress-response - some sort of response unrelated to anoxia - we applied the following control. Mice were again placed inside of $50 \mathrm{ml}$ conical tubes, but with the caps of the tubes left open, thus allowing the animals to breath normally, even though they were constrained "inside a tube" ("I.T."). To parallel the HPC treatments above, mice were restrained in these open-tubes for roughly the same mean-times as during the sequence of HPC: $200 \mathrm{~s}$, then $350 \mathrm{~s}$, then $600 \mathrm{~s}$.

All mice were utilized at P26 and were randomly assigned to the various treatment-conditions that we intended to study. Since we knew from the literature that the responses elicited by HPC usually last up to 7 days (Emerson et al., 1999; Rybnikova and Samoilov,

\section{Hypoxia tolerance time}

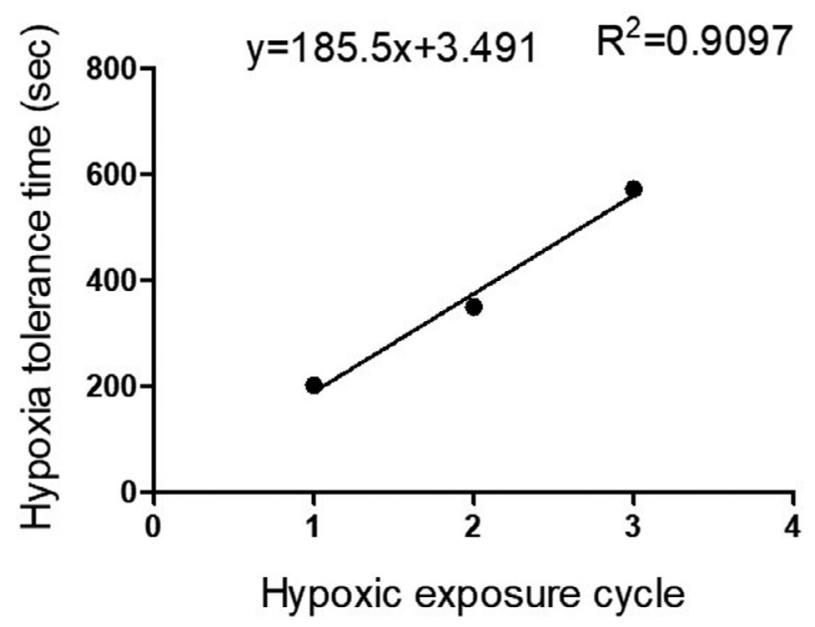

Fig. 1. Tolerance is developed after hypoxic exposure. Linear regression showing that after each run of hypoxic preconditioning $(1-3)$ the tolerance is consistently increased, $n=9$.
2015), we chose to study the response of the VMC in each mouse, every day for seven days after the HPC. To do so, their cerebellae were processed as described below. (The number of animals we used in each experimental procedure is shown in Table 2).

\section{Behavioral tests}

To determine the impact of HPC on the animals' subsequent motor behavior, we performed a battery that screened motor coordination. This included an accelerated version of the rotarod test, the statics rod test, and the horizontal bar test (Brooks and Dunnett, 2009; Deacon, 2013). All equipment was cleaned with $10 \%$ alcohol after each trail to prevent any olfactory cues. CD1 male mice underwent HPC at P26. Eight groups were tested and compared: Control group $(n=10)$, $24 \mathrm{~h}$ after HPC day $1(n=6), 48 \mathrm{~h}$ after HPC day 2 $(n=8), 72 \mathrm{~h}$ after HPC day $3(n=8), 96 \mathrm{~h}$ after HPC day $4(n=9), 120 \mathrm{~h}$ after HPC day $5(n=8), 144 \mathrm{~h}$ after HPC day $6(n=9), 168 \mathrm{~h}$ after HPC day $7(n=9)$. Each mouse was tested on every apparatus in a single session.

To determine motor coordination, we used the staticrods test (Deacon, 2013). Mice were placed on the last $5 \mathrm{~cm}$ of various rods, placed high over an overhang. Faced with this, mice spontaneously turn around and back up the rod to the fixed end. Mice were tested on various rods, starting with quite wide rods, but ending up with a tippy, $9 \mathrm{~mm}$ wide rod. The maximum time that each mouse took to turn around and walk back to the fixed end of the rod was scored. When a mouse fell off the rod or could not stay upright, it was assigned the maximum test time.

After a brief rest, coordination and forelimb-strength were evaluated with the Horizontal Bar test. This involved placing mice on the central part of a metal bar, hanging by their forepaws. Normally, mice can hang like this for roughly $30 \mathrm{~s}$. So, we recorded if they fell off before $30 \mathrm{~s}$. (Mice were also considered to have reached $30 \mathrm{~s}$, if they reached the end columns of the bar or touched a column with one forepaw). The metal bar was $38 \mathrm{~cm}$ long and was $49 \mathrm{~cm}$ above the floor; 3 diameters were tested $(2 \mathrm{~mm}, 4 \mathrm{~mm}, 6 \mathrm{~mm})$.

Finally, the animals were tested in a Rotarod (Series 8, IITC Life Science) to assess motor coordination. In the training phase, the animals underwent 3 sessions of $1 \mathrm{~min}$ with a fixed rotation of $5 \mathrm{rpm}$. In the test phase, the rod started at $5 \mathrm{rpm}$ but gradually increased to $40 \mathrm{rpm}$, (at an acceleration rate of $20 \mathrm{rpm} / \mathrm{min}$ ). Each mouse was subjected to three trials, with $2 \mathrm{~min}$ maximum for each trial. The distance, time and maximum acceleration of animals on the rod was recorded for each trail. One-Way ANOVA On Ranks was performed for the static rod and parallel bars data. Rotarod data was analyzed using a One-Way ANOVA. (Table 2).

\section{Light sheet fluorescence microscopy}

To generate a high-density map of BG cells distribution, and to determine the effects of HPC on the organization of this group of cells, brain clarification was performed 
on brains of transgenic GFAP-EGFP mice that had undergone HPC, using the CLARITY technique we described elsewhere (González-González et al., 2017). Mice were euthanized 4 days after $\operatorname{HPC}(N=5)$ and compared to control $(N=6)$. LSFM (Olarte et al., 2018) was used to image the whole brain. Imaging was performed with a $2 \times$ objective as described in Stefaniuk et al., 2016, using the $488 \mathrm{~nm}$ line of a diode laser (Cobolt 06-MLD) for exciting EGFP.

For image reconstruction of the cerebellum, stacks of $2096 \times 1705 \mu \mathrm{m}$ were stitched together with Fiji plugin (Preibisch et al., 2009). Each stack consisted of a horizontal scan of the cerebellum as shown in Fig. 3A. From each reconstruction, a three-dimensional region of interest (ROI) of $2.73 \times 10^{7} \mu \mathrm{m}^{3}$ was selected from (1) the cerebellar vermis and, (2) the cerebellar hemispheres (Fig. 3B). To determine the number of BG somata, the EGFP signal expressed under the GFAP promoter was localized by automated cell counting, using the centroid-localization function in each ROI with MATLAB software, as follows: background subtraction of every $\mathrm{ROI}$ was done; each image was binarized by computing a global threshold; centroid calculation was performed, and the number of centroids was displayed. Unpaired $t$-test was used to compare each lobule (Crus I, I, X, Crus II and V \& VII from day 4 post-HPC cerebella) against its corresponding lobule in controls. To compare data obtained from all lobules, One-Way ANOVA tests were run (Table 2).

\section{Tissue processing}

Brain fixation was performed to analyze the EGFP-signal from the VMC and from cerebellar lobule I in transgenic GFAP-EGFP mice, HPC was induced at P26 in 7 mice groups, and each group was euthanized one day after the next, for a whole week (Table 2). After intraperitoneal anesthesia with pentobarbital, mice were fixed transcardiac perfusion as previously described (Gage et al., 2012; González-González et al., 2017). This involved perfusion with $4 \%$ formaldehyde in phosphate-buffered saline $\left(137 \mathrm{mM} \mathrm{NaCl}, 2.7 \mathrm{mM} \mathrm{KCl}, 10 \mathrm{mM} \mathrm{Na}_{2} \mathrm{HPO}_{4}\right.$, and $2 \mathrm{mM}$ $\mathrm{KH}_{2} \mathrm{PO}_{4}$ in deionized water, $\mathrm{pH}=7.4$ ). After perfusion, whole cerebellae were excised and transferred to the same $4 \%$ PFA fixative at $4{ }^{\circ} \mathrm{C}$ for $24 \mathrm{~h}$. For imaging, the surfaces of lobules I, II and $X$ were exposed, those that were in contact with the CSF of the fourth ventricle (González-Gonzá lez et al., 2017).

\section{Imaging}

Whole brains were imaged with a Zeiss LSM 510 confocal microscope, utilizing a Zeiss 10X EC Plan-NEOFLUAR, $\mathrm{NA}=0.3, \quad W D=5.2 \mathrm{~mm}$ objective lens. Stacks of images of lobule I along the VMC were rendered in ImageJ. To determine the integrated fluorescent signal from GFAP-EGFP mice, renderings were analyzed after calibration from the original $10 \times$ image, then, renderings were binarized with Otsu's algorithm and subtracted from the original image to measure the integrated density from lobule I $(\mathrm{ROI}=902.70 \times 672.60 \mu \mathrm{m})$ and the VMC $(\mathrm{ROI}=38.94 \times 265.5 \mu \mathrm{m})$. One-way ANOVA was used in both, the lobule $I$ and the VMC to determine statistically significant differences between the means of the 7 post-HPC groups plus control group.

For analyzing the EGFP-signal specifically from BG in lobule I, coronal cerebellar cryo-sections were obtained after intracardiac perfusion and cryoprotection with increasing concentrations of sucrose $(10 \%, 20 \%$, and $30 \%$ in PBS) (González-González et al., 2015, 2017). Five consecutive $40 \mu \mathrm{m}$ coronal slices were collected from all 7 groups that underwent HPC at P26. Here, the Zeiss LSM-510 confocal microscope was equipped with a 20X Zeiss Plan-APOCHROMAT, NA $=0.8$, $\mathrm{WD}=0.55 \mathrm{~mm}$ objective. This was used to generate $40 \mu \mathrm{m}$ stacks wherein the EGFP-signal expressed in the BG somata could be quantified in ImageJ, with the cell counter plugin and a One-way ANOVA test was run to compare groups (Table 2).

\section{Rapid Golgi staining}

Morphological analysis of Bergmann glial cells was also performed after rapid Golgi staining. This was performed on cerebellae that were perfusion-fixed as indicated above, then subjected to the Golgi procedure as modified by Rosas-Arellano et al. (Diaz-Cintra et al., 1981; Shiga et al., 1983; Rosas-Arellano et al., 2007). This involved post-fixing cerebellar sagittal sections in $4 \%$ potassium dichromate in buffered formalin, then transfer to the classical rapid Golgi fixative for 6-11 days, then impregnation in a $0.75 \%$ silver nitrate solution for 18 $48 \mathrm{~h}$, and finally dehydration and embedding in nitrocellulose. From these samples, $120 \mu \mathrm{m}$ sagittal sections were obtained with a Leica, VT1000S vibratome. Bergmann glial cells of lobule I were imaged with an Olympus Ckx41 light microscope using a $40 \times$ objective. Forty-five cells from each animal were imaged and processed with ImageJ software. The diameter and area of the soma, as well as the absolute protrusion-length, were evaluated, as previously reported (Hanke and Reichenbach, 1987). Images were processed with the open source ImageJ software (version 1.51r, Wayne Rasband, National Institutes of Health, Bethesda). Huang's algorithm was applied for thresholding on Bergmann glia in Golgi samples, and the unpaired $t$-test was used to compare the four- and seven-day post-HPC groups.

\section{Western blot}

Western blotting was performed to determine the expression level of GFAP, ALDH1L1, Iba1, NeuN, and Nestin in GFAP-EGFP and CD1 strains, with actin used as loading-control. Total protein extracts from cerebellae $(n=4)$ were obtained. Tissue was processed and homogenated in ice-cold $200 \mathrm{mM}$ glycine buffer (with $150 \mathrm{mM} \mathrm{NaCl}, 50 \mathrm{mM}$ EGTA, $50 \mathrm{mM}$ EDTA, and $300 \mathrm{mM}$ sucrose, and containing a protease inhibitor (Sigma-Aldrich, USA Cat. No. P8340)). The homogenate was centrifuged twice at $10,000 \times g$ for $15 \mathrm{~min}$ at $4{ }^{\circ} \mathrm{C}$, and the supernatants were collected and stored at $-80^{\circ} \mathrm{C}$. Protein concentration was assessed by Bradford's method (Bradford, 1976). Equal concentrations $(30 \mu \mathrm{g})$ of total proteins were resolved on $10 \%$ SDSpolyacrylamide gel and transferred to a polyvinylidene 
difluoride membrane (Millipore, USA). Then, the membranes were blocked with $5 \%$ non-fat milk powder with $1 \mathrm{X}$ TBS-T for $3 \mathrm{~h}$. Membranes were incubated at $4{ }^{\circ} \mathrm{C}$ overnight with one of the primary antibodies shown in Table 1, and actin was used as an internal control for each sample. Then the membranes were washed with $1 \mathrm{X}$ TBS-T three times and incubated for $4 \mathrm{~h}$ with the secondary antibody (see Table 1). Alkaline phosphatase activity was detected with 5-Bromo-4-chloro-3-indolyl phosphate disodium salt (BCIP)/nitro blue tetrazolium chloride (NBT) according to the manufacturer's instructions. The Images were acquired with a Molecular Imager ChemiDoc XRS System (Bio-Rad Laboratories, Inc., USA), and optical density of trace quantity for each band was determined using Image Lab 2 software (Bio-Rad Laboratories Inc.).

\section{Immunofluorescence}

NeuN. We tried to understand whether the changes of expression of NeuN detected by Western blot (see below) were related to the response of neurons in the area, thus we examined the area by immunofluorescence 4 days after HPC using a NeuN monoclonal antibody (Table 1) in cryoprotected cerebellar coronal slices of CD1 mice. An unpaired $t$-test was used to analyze collected data for both analyses: cell number and integrated density.

Iba1. The distribution and morphology of microglial cells from lobule I were assessed 4 days after HPC by immunofluorescence using an Iba1 polyclonal antibody (Table 1) in cerebellar coronal slices of CD1 and Pax2GFP mice (Parmigiani et al., 2015) followed by the secondary antibody (Table 1), coronal slices comprising caudate putamen, lateral ventricles and corpus callosum were used as positive control (as microglia is equally widespread along the entire CNS) and sections incubated with the antibody diluent alone and no primary antibody, followed by secondary antibody and detection reagent was used as negative control. A Zeiss LSM 780 confocal microscope was used to image $15 \mu \mathrm{m}$ stacks at $1 \mu \mathrm{m}$ interval with a $20 \times$ objective. We analyzed the microglial population within the lobule I and the ventromedial cord in both strains since there were no differences between them the results were pooled together.

For the analysis of the number of lba1 + cells, we divided these cells into two groups: (1) cells with soma area equal to or less than $50 \mu \mathrm{m}$ corresponding to "resting" microglia, and (2) cells with soma larger than $50 \mu \mathrm{m}$ corresponding to "activated" microglia (Davis et al., 2017). Each image stack was analyzed using Fiji software as follows: (1) The stack was projected in the Z-axis into a single image using the maximum intensity projection type. (2) The contrast was enhanced using a 0.1 value in all cases. (3) The resulting image was converted into a binary, 8-bit format. (4) A threshold was applied using the triangle algorithm. (5) The image was cropped into a limited area $(450 \mu \mathrm{m} \times 300 \mu \mathrm{m})$ that included the SVZ and a portion of the granular layer. (6) A line grid of $1000 \mu \mathrm{m}^{2}$ was placed on the projection. (7) Each cell body labeled by the Iba1 antibody was drafted by hand with the freehand lasso tool and converted into a ROI. (8) The area and perimeter of each soma were obtained after applying the "Measure" function.

For assessing lba1 + cell distribution, each confocal image was divided into two zones based on a line grid of $1000 \mu \mathrm{m}^{2}$ : (1) The SVZ, ventrally delimited by the first 2 rows. (2) The supra SVZ that corresponded to the molecular, Purkinje and granular layers that covered 8 rows above the SVZ. The cell counter plugin was used to assess the number of lba1+ cells per zone (SVZ and supra SVZ).

\section{Bromodeoxyuridine (BrdU) incorporation assay}

To test cell proliferation after HPC, we used the thymidine analog (BrdU, Sigma-Aldrich Cat. No. B5002). Two CD1 mice groups were used: Control $(n=3)$ and four days after HPC $(n=3)$. Lateral ventricles served as a control

Table 1. List of antibodies used in this study. WB $=$ Western blot, IF $=$ Immunofluorescence

\begin{tabular}{|c|c|c|c|c|}
\hline $1 \mathrm{AB}$ & {$[1 \mathrm{AB}]$} & Reacts with & $2 \mathrm{AB}$ & {$[2 \mathrm{AB}]$} \\
\hline $\begin{array}{c}\text { Polyclonal rabbit anti-GFAP - Santa Cruz } \\
\text { Biotechnology Inc. - Cat. No. sc-6171 }\end{array}$ & $1: 2000$ & Glial Fibrillary Acidic Protein & $\begin{array}{l}\text { Goat anti-rabbit IgG-AP - Santa Cruz } \\
\text { Biotechnology, Inc. - Cat. No. sc-2034 }\end{array}$ & $\begin{array}{l}\text { WB: } \\
1: 2500\end{array}$ \\
\hline $\begin{array}{l}\text { Monoclonal mouse anti-NeuN - Merck - } \\
\text { Cat. No. MAB377 }\end{array}$ & $1: 2000$ & $\begin{array}{l}\text { DNA-binding neuron-specific } \\
\text { protein NeuN }\end{array}$ & $\begin{array}{l}\text { Goat anti-Mouse IgG }(\mathrm{H}+\mathrm{L})-\text { Thermo } \\
\text { Fisher - Cat. No. R37121 } \\
\text { Goat anti-mouse IgG-AP - Santa Cruz } \\
\text { Biotechnology, Inc. - Cat. No. sc-2058 }\end{array}$ & $\begin{array}{l}\text { IF: } \\
1: 1000 \\
\text { WB: } \\
1: 2500\end{array}$ \\
\hline $\begin{array}{l}\text { Polyclonal rabbit anti-lba1 - Wako - Cat. } \\
\text { No. 019-19741 }\end{array}$ & 1:1000 & $\begin{array}{l}\text { Calcium-binding protein Iba1 } \\
\text { specifically found in microglia }\end{array}$ & $\begin{array}{l}\text { Goat anti-Rabbit IgG }(\mathrm{H}+\mathrm{L}) \text { Superclonal } \\
\text { Alexa Fluor } 647 \text { - Invitrogen Cat No. A27040 } \\
\text { Goat anti-rabbit IgG-AP - Santa Cruz } \\
\text { Biotechnology, Inc. - Cat. No. sc-2034 }\end{array}$ & $\begin{array}{l}\text { IF: } \\
1: 1000 \\
\text { WB: } \\
1: 2500\end{array}$ \\
\hline $\begin{array}{l}\text { Monoclonal mouse anti-nestin - BD } \\
\text { Transduction Laboratories - Cat. No. } \\
611659\end{array}$ & $1: 5000$ & $\begin{array}{l}\text { Intermediate filament type VI } \\
\text { nestin }\end{array}$ & $\begin{array}{l}\text { Goat anti-mouse IgG-AP - Santa Cruz } \\
\text { Biotechnology, Inc. - Cat. No. sc-2058 }\end{array}$ & $\begin{array}{l}\text { WB: } \\
1: 2500\end{array}$ \\
\hline $\begin{array}{l}\text { Polyclonal rabbit anti-ALDH1L1 - Abcam } \\
- \text { Cat. No. ab87117 }\end{array}$ & 1:1000 & Astrocytes & $\begin{array}{l}\text { Goat anti-rabbit lgG-AP - Santa Cruz } \\
\text { Biotechnology, Inc. - Cat. No. sc-2034 }\end{array}$ & $\begin{array}{l}\text { WB: } \\
1: 2500\end{array}$ \\
\hline $\begin{array}{l}\text { Polyclonal goat anti-actin - Santa Cruz } \\
\text { Biotechnology Inc. - Cat. No. sc1616 }\end{array}$ & $1: 2500$ & Actin protein & $\begin{array}{l}\text { Rabbit anti-goat IgG-AP - Santa Cruz } \\
\text { Biotechnology, Inc. - Cat. No. sc-2949 }\end{array}$ & $\begin{array}{l}\text { WB: } \\
1: 2500\end{array}$ \\
\hline Anti-BrdU - Bio-Rad Cat. No. OBT0030 & 1:1000 & Cell proliferation rate & $\begin{array}{l}\text { Biotinylated Goat Anti-Rat IgG - Vector } \\
\text { Laboratories Cat. No. BA-9400 }\end{array}$ & $\begin{array}{l}\text { IF: } \\
1: 2000\end{array}$ \\
\hline
\end{tabular}


Table 2. Experimental designs. $N=$ Population size, $n=$ Sample size, $\mathrm{Cb}=$ Cerebellum, VMC $=$ Ventromedial cord, $\mathrm{BG}=$ Bergmann glia

\begin{tabular}{|c|c|c|c|c|c|c|}
\hline Experiment & $\begin{array}{l}\text { Mouse } \\
\text { strain }\end{array}$ & $\begin{array}{l}\text { Experimental } \\
\text { unit }\end{array}$ & Observational unit & $N$ & $n$ & Statistical analysis \\
\hline Behavioral tests: & CD1 & Mice & Motor task & 67 & $6-10$ & \\
\hline Rotarod & & & & & & $\begin{array}{l}\text { - One-way ANOVA (rotarod) - Post } \\
\text { hoc: Tukey's }\end{array}$ \\
\hline $\begin{array}{l}\text { Static rods Parallel } \\
\text { bars }\end{array}$ & & & & & & - One-way ANOVA on Ranks \\
\hline Light sheet & $\begin{array}{l}\text { GFAP- } \\
\text { EGFP }\end{array}$ & Mice & $\mathrm{Cb}$ lobules & 11 & 55 & $\begin{array}{l}\text { - Unpaired T-test (Each HPC lobule } \\
\text { vs corresponding control lobule) } \\
\text { - One Way ANOVA - Post hoc: } \\
\text { Tukey's }\end{array}$ \\
\hline Whole-mount & $\begin{array}{l}\text { GFAP- } \\
\text { EGFP }\end{array}$ & Mice & $\begin{array}{l}\text { GFAP- positive cells from the fourth } \\
\text { ventricle surface of Lobule I and VMC }\end{array}$ & 24 & 3 & $\begin{array}{l}\text { - One Way ANOVA - Post hoc: } \\
\text { Tukey's }\end{array}$ \\
\hline Cryostat sectioning & $\begin{array}{l}\text { GFAP- } \\
\text { EGFP }\end{array}$ & Mice & $\begin{array}{l}\text { GFAP- positive cells from VMC and } \\
\text { molecular layer }\end{array}$ & 24 & 3 & $\begin{array}{l}\text { - One Way ANOVA - Post hoc: } \\
\text { Tukey's }\end{array}$ \\
\hline Ectopic BG & & & $\begin{array}{l}\text { GFAP-positive ectopic BG from the } \\
\text { molecular layer }\end{array}$ & & & - Unpaired $t$-test \\
\hline Rapid Golgi & CD1 & Mice & BG from Lobule I & 9 & 45 & - Unpaired $t$-test \\
\hline Western Blot (1) & $\begin{array}{l}\text { GFAP- } \\
\text { EGFP }\end{array}$ & Mice & $\mathrm{Cb}$ total protein & 36 & 4 & $\begin{array}{l}\text { - One Way ANOVA - Post hoc: } \\
\text { Tukey's }\end{array}$ \\
\hline Western Blot (2) & $\begin{array}{l}\text { GFAP- } \\
\text { EGFP vs } \\
\text { CD1 }\end{array}$ & Mice & $\mathrm{Cb}$ total protein & 54 & 3 & $\begin{array}{l}\text { - One Way ANOVA - Post hoc: } \\
\text { Tukey's }\end{array}$ \\
\hline IF- (NeuN) & CD1 & Mice & $\left(\mathrm{NeuN}^{+}\right)$from molecular layer & 6 & 3 & - Unpaired $t$-test \\
\hline IF-microglia (Iba1) & $\begin{array}{l}\text { Pax2-GFP } \\
\text { and CD1 }\end{array}$ & Mice & Microglia $\left(\mathrm{Iba} 1^{+}\right)$from molecular layer & 12 & $9-15$ & - Unpaired $t$-test \\
\hline BrdU & $\begin{array}{l}\text { GFAP- } \\
\text { EGFP and } \\
\text { CD1 }\end{array}$ & Mice & VMC & 6 & 3 & - Unpaired $t$-test \\
\hline
\end{tabular}

since active BrdU incorporation has been widely reported in the area. Cerebellar slices incubated with the antibody diluent alone and no primary antibody, followed by secondary antibody and detection reagent were used as a negative control.

For each group, two I.P. injections of $50 \mu \mathrm{g} / \mathrm{g} \mathrm{BrdU}$ $(10 \mathrm{mg} / \mathrm{mL})$ were administered every $6 \mathrm{~h}$. The first injection was performed $30 \mathrm{~min}$ after HPC, and daily doses of BrdU were given for 5 days. Mice were euthanized $2 \mathrm{~h}$ after the last injection and brains were processed as described above. Cryoprotected cerebella were sliced into $40 \mu \mathrm{m}$ coronal sections and observations focused on lobule I.

BrdU was detected using anti-BrdU 1:1000 (Bio-Rad. Cat. No. OBT0030), followed by the secondary antibody: Biotinylated Goat Anti-Rat IgG Antibody 1:2000 (Vector Laboratories. Cat. No. BA-9400) (Table 1). Later, samples were incubated in AvidinBiotin Complex $(A B C)$ and revealed using tyramide signal amplification (TSA) plus coumarin (1:100, Perkin Elmer. Cat. No. NEL703001KT) according to the manufacturer's instructions.

\section{Statistical analyses}

Statistical analyses were performed using the following software: GraphPad Prism version 5.0 for Windows (GraphPad Software, La Joya, California, USA). All data were plotted on SigmaPlot (Systat Software, San Jose, CA). Statistical analysis of each experimental procedure is detailed in Table 2.

\section{RESULTS}

\section{HPC does not significantly alter motor coordination}

It is known that extreme hypoxic conditions can impair motor coordination, likely due to cerebellar damage (Benitez et al., 2014). To determine whether HPC itself might also impair motor coordination, we conducted the following tests: (1) an accelerating version of the rotarod test, (2) the static rods test, and (3) the horizontal bar test. None of these tests revealed any significant disturbances to motor coordination after HPC. Only a very slight deterioration in performance on the rotarod test, 6 days after HPC, could be gleaned, and only after analyzing the results with Tukey's post hoc test (Kim, 2015).

The static rods and parallel bars tests showed no significant differences, although we noticed that HPCtreated mice took a bit more time to cross over the rods and hung onto the bars a bit less tenaciously. In general, though, it was clear that HPC did not induce any gross motor-deficits (Fig. 2).

\section{Changes in Bergmann glia (BG) organization and morphology}

A global analysis of EGFP expression in the cerebellum after HPC was achieved by LSFM in clarified samples of transgenic GFAP-EGFP mice. No further immunofluorescence was required, because endogenous fluorescence from formaldehyde fixations was well preserved after clarification. This allowed us to observe the tight palisade that BG processes form, 

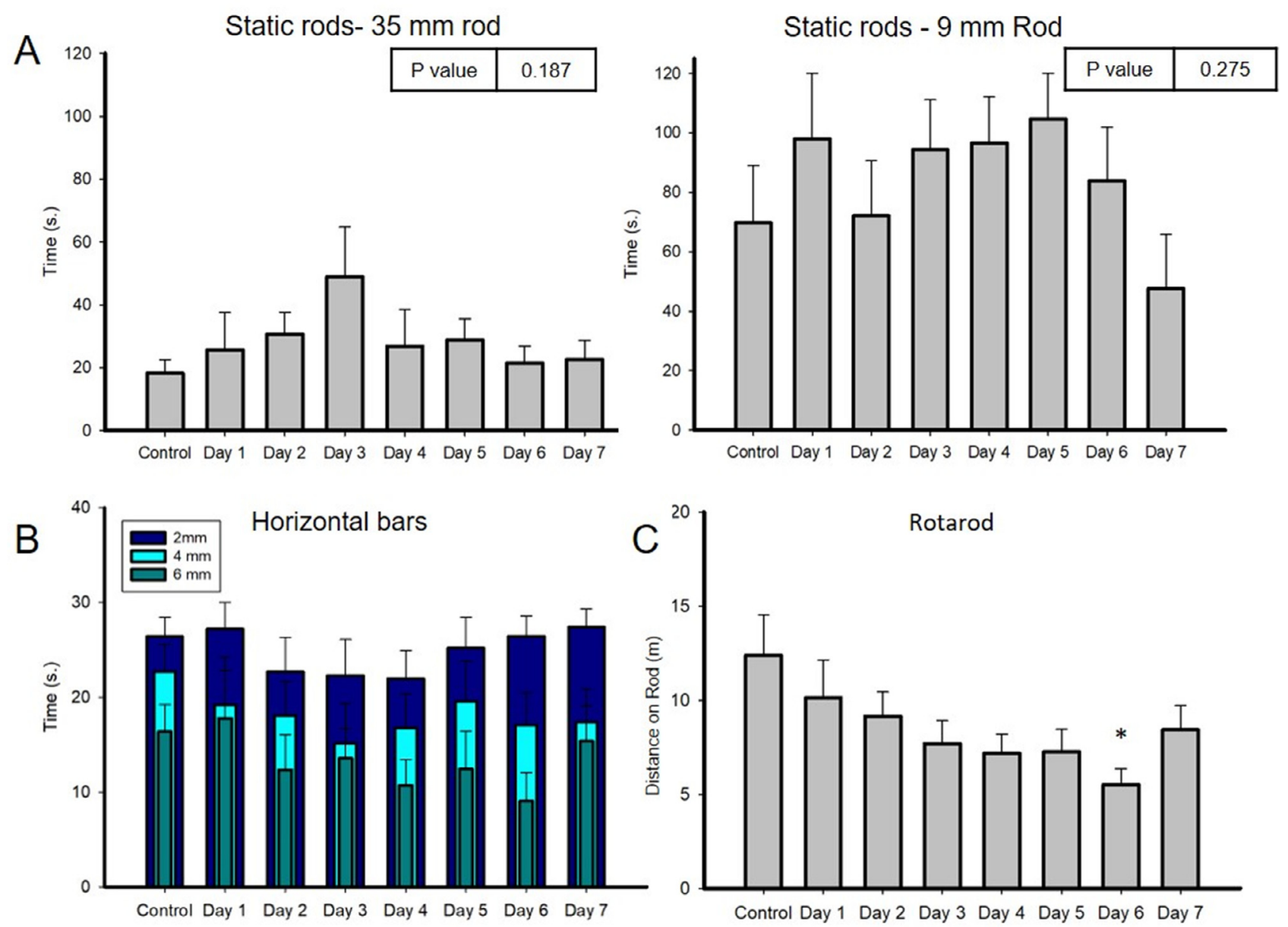

\begin{tabular}{|c|c|}
\hline $2 \mathrm{~mm} P$ value & 0.793 \\
\hline $4 \mathrm{~mm} P$ value & 0.843 \\
\hline $6 \mathrm{~mm} P$ value & 0.477 \\
\hline
\end{tabular}

Fig. 2. HPC does not affect gross motor activity. (A): Static Rods. Performance on the widest $(35 \mathrm{~mm})$ and the narrowest rod (9 mm) are displayed; $28 \mathrm{~mm}, 22 \mathrm{~mm}$, and $15 \mathrm{~mm}$ were also tested. Shorter execution times on the rod indicated better motor coordination, the control group maintained a better execution for both graphs. (B): Horizontal bars. Mice tested 2-5 days after HPC lasted less time hanging on the bars (2-6 mm), suggesting slight problems in motor coordination and reduced strength in limbs; however, data were not statistically different. (C): Rotarod test. A longer distance correlates with better motor coordination. Shorter distances were recorded from 1 day after HPC, and the only statistically significant difference was found at day $6\left(F_{(7,191)}=2.347, P\right.$ value $=0.024$; Tukey's post-hoc test). Mice recovered at day 7 .

viewed right through the molecular layer of the cerebellum (Fig. 3A). Vermis and hemispheres showed statistical differences in the number of EGFP + BG somata as determined by One-Way ANOVA and Tukey as posthoc $\left(F_{(9,62)}=3.263, P\right.$ value $\left.=0.0026\right)(F i g .3 C)$. No significant differences were found when comparing each lobule, as determined by the unpaired $t$-test.

The only difference we could find after HPC was a reduction in the number of $B G$ somata in the lobules of the vermis, and a larger number of somata in the hemispheres, which may be worthy of further analysis. Fig. 3A, B shows sample images from cerebella of GFAP-EGFP mouse and Fig. $3 \mathrm{C}$ contrasts the number of EGFP + cells from diverse areas of the cerebellum from control and HPC mice. The overall reduction in the number of EGFP + cells seen here after HPC should not be interpreted as an actual loss of GFAP + cells.
Rather, we will show below that it simply represents a reduction in the expression of the reporter gene.

\section{EGFP expression in the VMC is decreased after HPC}

Since the CSF responds quickly to metabolic changes like those expected after HPC, we analyzed whether the VMC, which we showed earlier is an array of GFAP+ and nestin + ependymal cells that contact the CSF (Gon zález-González et al., 2017), also displayed a reduction in EGFP-expression. Our en face preparations exposed the VMC along lobule I, which is the area we analyzed. Indeed, we could clearly observe a gradual decrease in EGFP expression for some days after HPC in the VMC but also in the GFAP + ependymal cells lining the lobule I. In the latter, the lowest expression was reached by day 4, after which EGFP expression rebounded and held 
A

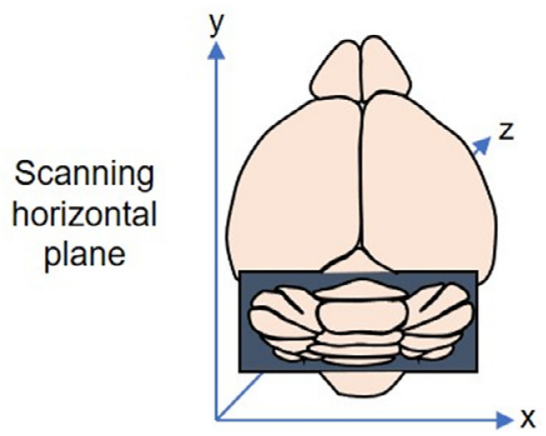

Optical slice

(2D)
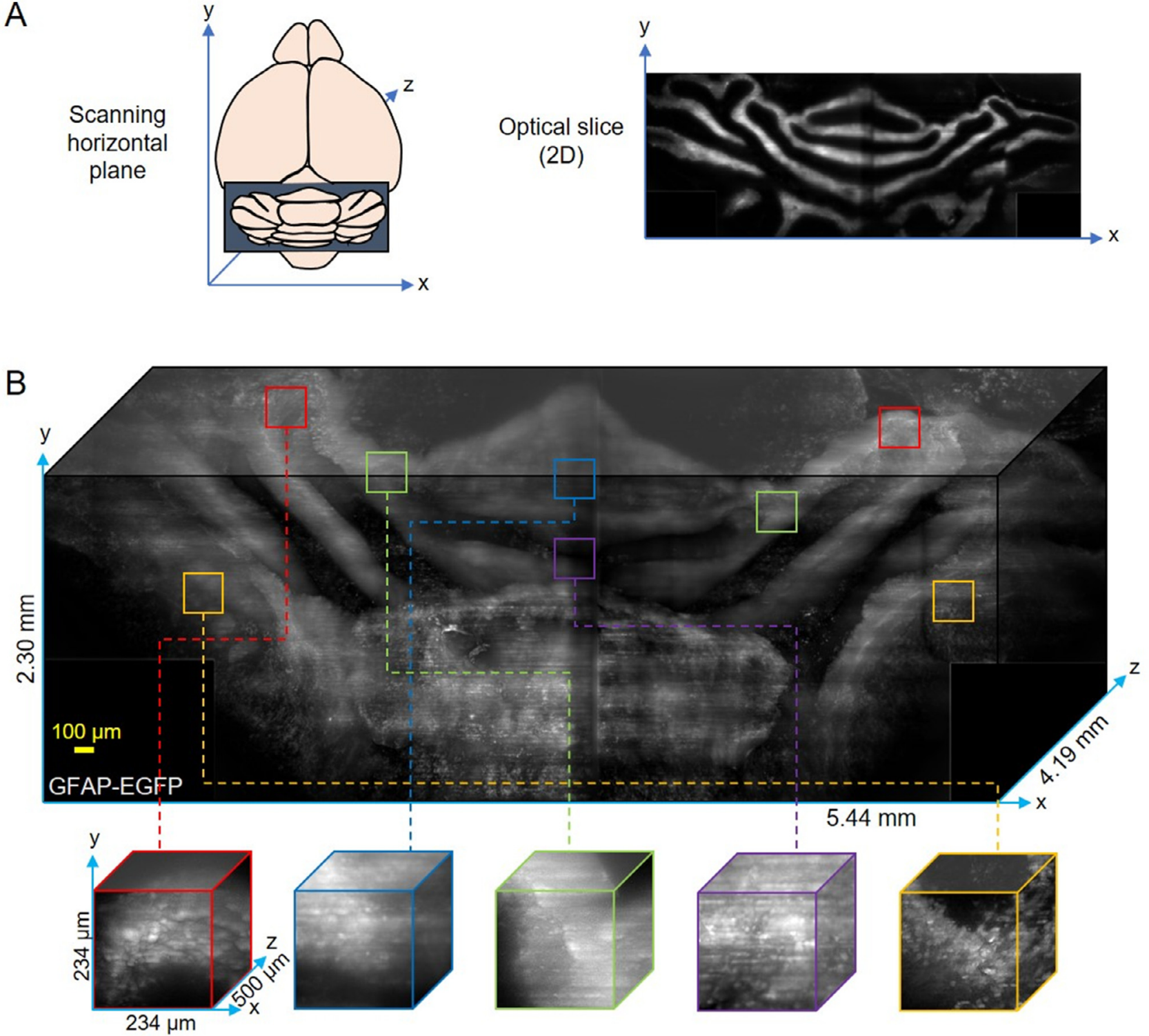

C

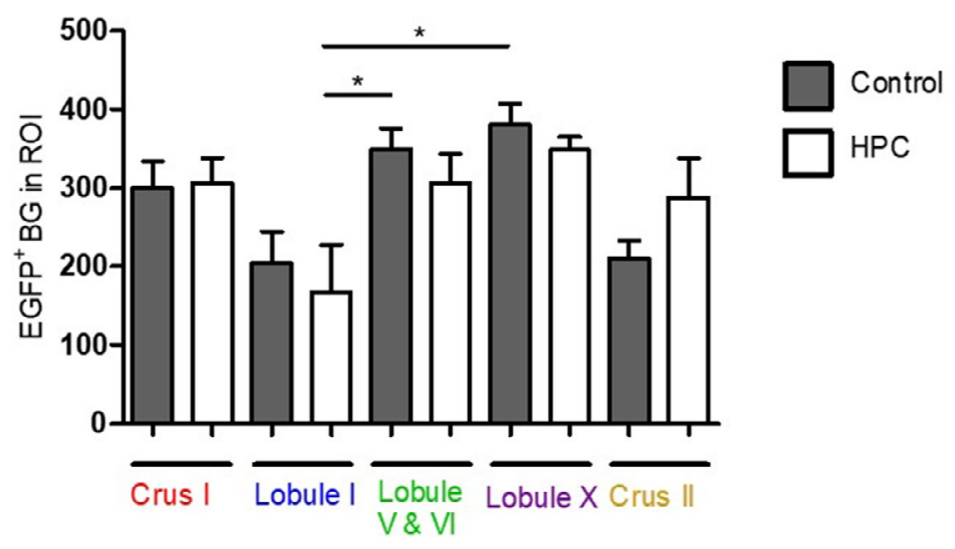


steady thereafter (Fig. 4A). Integrated density analysis of the images supported this observation, since the lowest pixel density was determined on day 4 (Fig. 4B), which differed from the control (One-Way ANOVA $\left(F_{(7,16)}=4.419, P\right.$ value $\left.=0.0066\right)$. EGFP expression also decreased in the VMC (Fig. 4C). Also, by day 4, the VMC appeared disorganized and the GFAP + cells that normally reside along the midline of lobule I were gone, as we showed previously (González-González et al., 2017). Integrated density analysis showed the lowest pixel density in the VMC by day 4 and gradual recovery starting on day 5 . Data reflected statistically significant differences as determined by One-Way ANOVA $\left(F_{(7,16)}=9.275, P\right.$ value $\left.=0.0001\right),(N=24, n=3)$.

\section{EGFP expression is decreased in the BG cells after HPC}

As mentioned above, BG cells of lobule I showed reduced EGFP expression in coronal slices viewed by confocal microscopy (Fig. 5A). Image analysis revealed a significant difference in the number of $B G$ somata that expressed EGFP, as determined by a one-way ANOVA, $\left(F_{(7,112)}=36.04, \quad p<0.0001\right.$ Tukey as post-hoc $)$ Fig. 5B $(n=3)$. Other morphological changes in $\mathrm{BG}$ that were notable after HPC included: (1) by day $1, B G$ somata were slightly displaced from the Purkinje cell layer, and did not return to their original positions until days 5-7; (2) BG processes expressed lower levels of EGFP until day $4-5$, after which they returned to their normal levels. Coincident with these changes, BG cellular processes retracted on day 1 and remained withdrawn until day 4-5 (an observation we could confirm by rapid Golgi analyses, below). Additionally, we noted that after HPC, the distribution of EGFP in BG terminal end-feet, which normally looks diffuse, temporarily became punctate from day 2 to 6 (Fig. 5C).

During our analyses of coronal sections from lobule I, we observed some totally ectopic BG cells, both in normal conditions and after HPC (Fig. 5A, B). These cells were recently described by Cerrato et al. (2018). To determine if these ectopic BG cells might respond differently to HPC than the others described above, we first counted them manually in slices from GFAP-EGFP mice; but as shown in Fig. 5D, their numbers and distributions did not change. We can conclude that majority of BG cells in lobule I of the cerebellum respond to HPC by changing their morphology and reducing their expression of EGFP. To further analyze these changes, we processed cerebella by the rapid
Golgi technique 4 days after HPC, when these cells showed the most pronounced changes.

\section{BG processes retracts after HPC}

The aforementioned differences found among BG cells by fluorescence microscopy prompted us to observe them more closely via silver impregnation at 4 and 7 days after HPC (Fig. 6A). This revealed that as they retracted their soma into the cerebellar parenchyma, their processes became commensurately longer. These morphological changes reached statistical significance, as determined by an unpaired $t$-test $(P$ value $<0.0001)$ (Fig. 6B). At day 4 the area of the soma was reduced by $31 \%$ ( $\mathrm{SE}=3.25, n=3, \mathrm{P}$ value $<0.0001)$, and by day 7 there was a slight recovery in the soma $(23 \%$ $\mathrm{SE}=2.69, \quad n=3, \quad P$ value <0.0001). Absolute protrusion length of the processes increased $88 \%$ by day 4 (SE $=2.54, n=3, P$ value $<0.0001)$ and persisted to $75 \%$ by day 7 (SE $=2.47, n=3, P$ value $<0.0001)$.

\section{Expression of glial and neuronal identity markers after HPC}

To assess changes in expression of selective glial and neuronal markers after induction of HPC, we isolated proteins from cerebella before and after HPC and analyzed the expression of GFAP, ALDH1L1, Iba1, NeuN, and nestin. Representative blots are shown in Fig. 7A, $n=4$ (for GFAP-EGFP mice) and Fig. 8 for CD1 mice. To discard the possibility of stress-induced changes in expression, we considered two control groups: (1) Control "inside a tube" (I.T.), in which the mice's movements were restrained but they were not made anoxic, because their snouts were outside the tube, so they could breathe normally; and (2) control "outside a tube" (O.T.): true controls of mice never constrained in any tubes. Astrocyte markers GFAP and ALDH1L1 expression started to decline one day after HPC, but by day 4 their expression began to rebound, and by day 6 it returned to control levels (Fig. 7B, C). Microglial marker Iba1 and neuronal marker NeuN increased their expression from day two after HPC and did not return to control levels even after one week (Fig. 7D, E). Nestin also showed an increased expression from day one after HPC and continued to display increasing expression until day 7 (Fig. 7F). Statistical analyses included One-Way ANOVA and Tukey as post-hoc, $(N=36, n=4)$.

Fig. 3. Distribution of Bergmann glial cells in the cerebellum from GFAP-EGFP mice. Clarified brains of GFAP-EGFP mice were observed under the light sheet fluorescence microscope. (A): Scanning plane of the light sheet and an example of one 2D optical slice. (B): Reconstruction of a $5.44 \times 2.30 \times 4.19 \mathrm{~mm}$ volume of cerebellum. Color squares indicate the ROls extracted for tridimensional stacks shown below. (C): A consistency in the reduction of the EGFP signal was observed in several areas of the cerebellum. No significant differences were found when comparing each lobule as determined by the unpaired $t$-test (Crus I: $P$ value $=0.8940,299.9 \pm 34.08(N=9)$ vs $306.2 \pm 32.03(N=9)$. Lobule I: $P$ value $=0.6277,204.0 \pm 40.42(N=6)$ vs $167.7 \pm 60.33(N=6)$. Lobule V \& VII: $P$ value $=0.3427,349.5 \pm 26.68(N=11)$ vs $305.5 \pm 38.10$ $(N=8)$. Lobule $X: P$ value $=0.3236,380.8 \pm 26.07(N=5)$ vs $348.0 \pm 17.11(N=5)$. Crus II: $P$ value $=0.1670,210.9 \pm 22.40(N=7)$ vs $288.0 \pm 50.18(N=6)(N=6$, Control), $(N=5$, HPC). Values are expressed as mean \pm SEM. GFAP: Glial fibrillary acidic protein, EGFP: Enhanced green fluorescent protein, BG: Bergmann glia, HPC: Hypoxic preconditioning. 


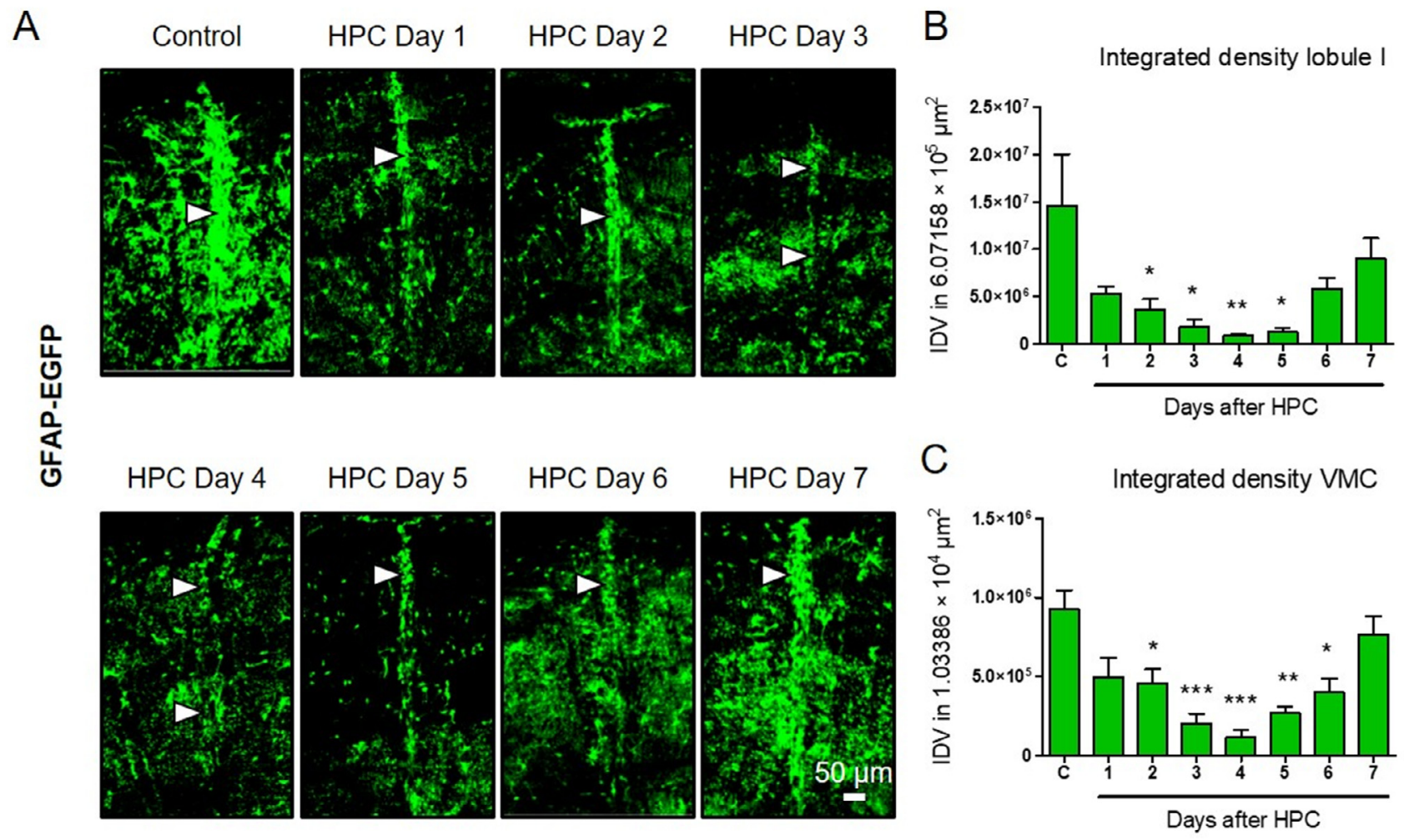

Fig. 4. EGFP expression after hypoxic preconditioning in the VMC of lobule I. The en face preparation exposed the VMC on the surface of the roof of the ventricle. (A): Confocal images of GFAP-EGFP mice cerebella. White arrowheads point to the VMC, which showed a gradual reduction of EGFP expression after HPC and recovered after day 4. (B): Image analysis showed that the EGFP signal decreased on the roof of the ventricle starting one day after HPC, and from days 2 to 5 the reduction was statistically different $\left(F_{(7,16)}=4.419, P\right.$ value $\left.=0.0066\right)$ as determined by a oneway ANOVA test (post hoc: Tukey), $(N=24, n=3)$. (C): Decreased EGFP signal was also observed in the VMC after HPC with a statistically significant reduction from days 2 to 6 and recovered by day $7\left(F_{(7,16)}=9.275, P\right.$ value $\left.=0.0001\right)$ as determined by a one-way ANOVA test (post hoc: Tukey). Values are expressed as mean \pm SEM. IDV: Integrated density values, HPC: Hypoxic preconditioning, GFAP: Glial fibrillary acidic protein, EGFP: Enhanced green fluorescent protein, VMC: Ventromedial cord.

Given the observed increase in NeuN expression, we checked to see if there was a change in the number of $\mathrm{NeuN}+$ cells in the molecular layer of the cerebellum after HPC, using two completely straightforward imageanalysis techniques: (1) manual cell counting, and (2) optical density. However, no differences in cell number were observed after four days of HPC (Fig. 9), so we can conclude that the increased NeuN in the blots must have been due to increased expression, not to production of new neurons.

\section{Enlargement of microglial somata after HPC}

The observed increase in Iba1 expression suggested that microglial cells might be affected by HPC. To evaluate this, we measured the sizes of microglia, using immunofluorescence of coronal slices from CD1 and Pax2-GFP mice cerebella. The data from both strains were similar and thus were pooled together to show that lba1 + cells were mostly distributed in the SVZ and supra SVZ (Fig. 10A). Although the overall number of lba1 + cells did not change in those areas after HPC $(P$ value $=0.1896, \quad 32.22 \pm 3.759 \quad(N=9) \quad$ vs 25.80 $\pm 2.810(N=15))$ (Fig. 10B), we could show by a closer analysis of the morphology of Iba1 + cells in the supra SVZ that their somas became slightly bigger around 4 days after HPC. At least, we observed a reduction in the number of cells whose soma-areas were below $50 \mu \mathrm{m}^{2}$ (i.e., "resting state") $(P$ value $=0.0003, \quad 15.89 \pm 1.711 \quad(N=9), \quad$ vs 7.667 \pm 1.054. $(N=15)) \quad$ (Fig. 10C, D). No statistically significant differences were found in the number of cells whose soma was larger than $50 \mu \mathrm{m}^{2}$ (i.e., "activated state") $(P$ value $=0.3402,7.778 \pm 1.854(N=9)$ vs $10.40 \pm 1.756(N=15))$. In all cases, we used an unpaired $t$-test $(p<0.05)$. Values are expressed as mean \pm SEM. Sample images of the Iba1 + cells are shown in panels of Fig. 10C, D in which the differences in soma areas are observed and the complexity of the processes is contrasted. Thus, it appeared that HPC induced a subtle response in microglial cells exclusively in the supra SVZ.

\section{Limited incorporation of BrdU after HPC}

Cells positive for nestin and GFAP in other areas of the brain than those studied here have already been shown to divide and differentiate after hypoxic conditions (Zhu et al., 2005; Horie et al., 2008). Thus, we were interested to see whether cells from the VMC would also incorporate $\mathrm{BrdU}$ after HPC. Coronal slices along lobule I were again used to image the VMC, but unfortunately, we could not 
A
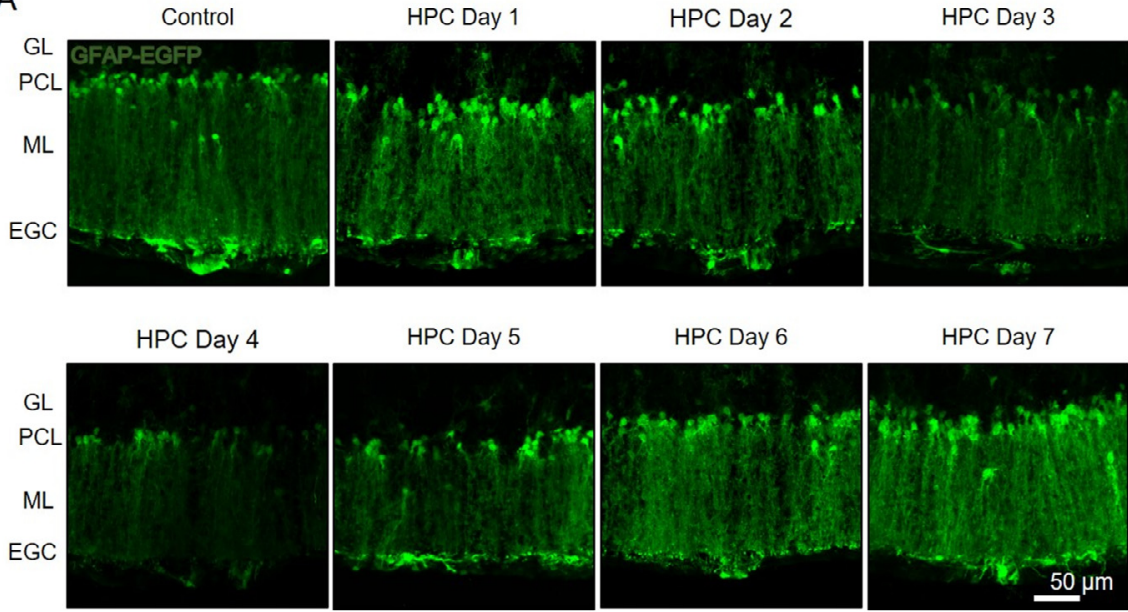

HPC Day 5
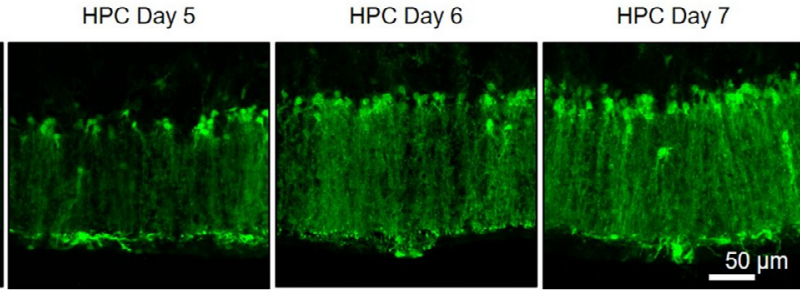

B

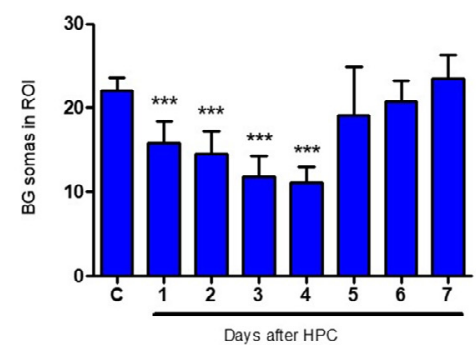

C

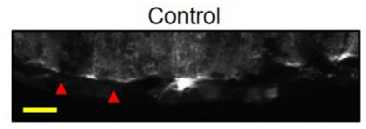

HPC Day 4

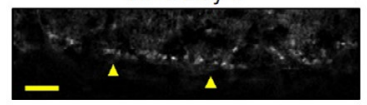

HPC Day 7

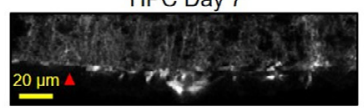

D
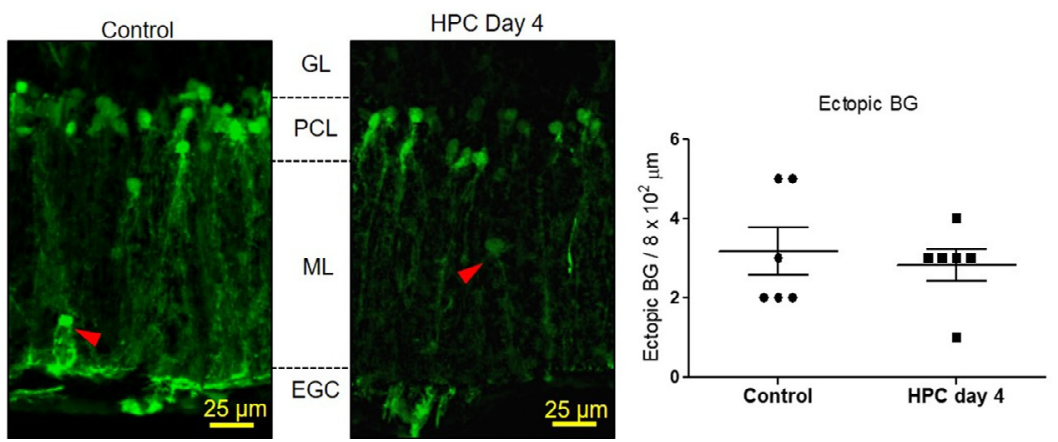

Fig. 5. Effect of HPC on Bergmann glial cells. Coronal slices of lobule I of GFAP-EGFP mice under the confocal microscope showed $(A)$ : a reduction in the number of BG somata that express EGFP 1 day after HPC and until day 4; the expression recovered by day 7. (B): Image analysis of the number of EGFP ${ }^{+}$BG somata revealed a significant difference from day 1 to 4 , with a subsequent recovery from day five $\left(F_{(7,112)}=36.04, P\right.$ value $\left.<0.0001\right)$ as determined by a oneway ANOVA test (post hoc: Tukey) $(N=32, n=4)$. Values are expressed as mean \pm SEM. (C) Terminal end-feet of BG as detected by EGFP appeared disorganized after HPC. Yellow arrowheads in panel day 4 point toward EGFP punctate pattern, which contrasts with the continuous fluorescence observed in control and after partial recovery at day 7 (red arrowheads). (D): Ectopic EGFP ${ }^{+}$BG were manually counted in coronal renderings of lobule I at day 4 after HPC. No differences were detected in cell number; red arrowheads point to displaced BG cells. HPC: Hypoxic preconditioning, GFAP: Glial fibrillary acidic protein, EGFP: Enhanced green fluorescent protein, GL: Granular layer, PCL: Purkinje cell layer, ML: Molecular layer, EGC: Ependymal glial cells. BG: Bergmann glia.

readily demonstrate any BrdU incorporation into this structure. All we could find was a bit of BrdU incorporation into the ependymal glial cells (EGC) on the roof of the ventricle, as well as a few cells in the molecular layer (Fig. 11B), consistent with our previous work (GonzálezGonzález et al., 2017). Furthermore, incorporation of $\mathrm{BrdU}$ in the floor of the fourth ventricle, that is in the
HPC Day 7

medulla, occurred at basal levels in the EGC and also in deep layers. Interestingly, BrdU incorporation was substantially increased four days after HPC in the medulla.

\section{DISCUSSION}

In the cerebellum, the roof of the ventricle includes two novel structures that we have named the subventricular cellular cluster (SVCC) and the ventromedial cord (VMC). The VMC is formed by GFAP + and nestin + ependymal cells whose morphology partially resembles radial glia (González-Gon zález et al., 2017). The close contact of these VMC cells with the CSF, the choroid plexus, and the underlying blood vessels, would seem to put them in an ideal position to sense variations in this important microenvironment. However, even though the VMC has been described in several mammalian species, such a functional role has never been disclosed (González-González et al., 2017).

To pursue this possibility, we sought here to show that cells in the VMC would respond to relatively mild biochemical changes in their environment, like those induced by HPC, wherein the application of repeated mild hypoxic episodes protects animals from later severe anoxia. We indeed found by imageanalyses of EGFP expression with LSFM that lobule-specific changes occurred upon HPC, with clear cut reductions in EGFP expression in lobules I and $X$, which form the roof of the ventricle and include the VMC. Additionally, we could show that HPC induces morphological changes in the VMC and in the BG cells of lobule I, and that HPC also leads to a transient reduction in the expression of certain astrocyte markers (GFAP and ALDH1L1), plus a prolonged, greater than one week, increase in expression of $\mathrm{NeuN}$, Iba1, and nestin.

Additionally, we documented here that microglia become activated for four days after HPC, specifically in the supra SVZ of lobule I of the cerebellum. On the other hand, we could not demonstrate any incorporation of BrdU into cells on the roof of the fourth ventricle after HPC, although we were surprised to find a robust incorporation of BrdU into cells on the floor of the fourth ventricle under all 

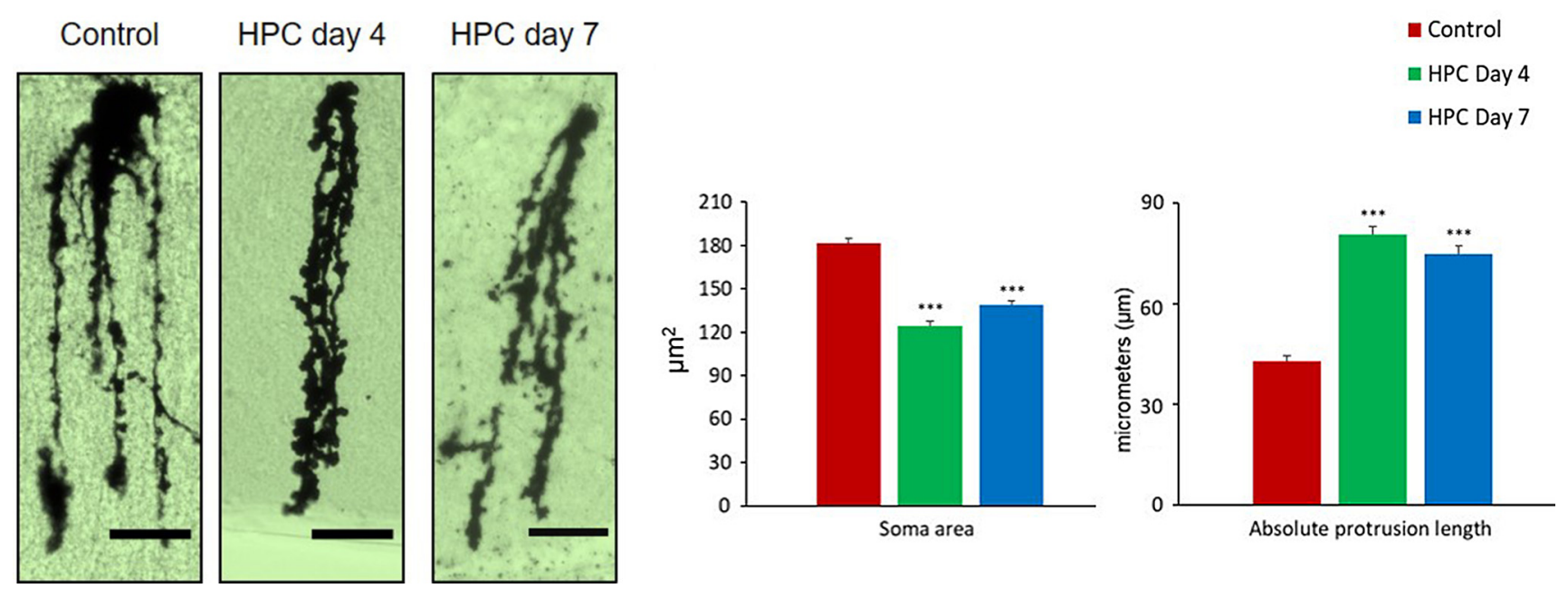

Fig. 6. Effect of HPC on the morphology of Bergmann glial cells. Golgi staining revealed fine differences: (A): sample images of BG cells 4 and 7 days after HPC. (B): The area of the somata were reduced and did not fully recover after 7 days. Additionally, processes retracted while absolute protrusion length was substantially increased and did not fully return to normal conditions at day 7 ( $P$ value $<0.0001,(N=3, n=45$ for each group: Control, HPC day 4, HPC day 7). Values are expressed as mean \pm SEM. HPC: Hypoxic preconditioning. Bar: $100 \mu \mathrm{m}$.

conditions, which became even more robust 4 days after HPC, a unique observation that we intend to pursue in future experiments.

The application of only one behavioral test would not be adequate to assess global motor dysfunction, so in order to determine whether HPC induces any motor disability, we here used a combination of motor tests after HPC. The rotarod is a commonly used tool for testing coordination, and deficits with it are particularly obvious in mice with altered cerebellar function. The static rods test (also a coordination test) has increased sensitivity compared to the rotarod, enabling the detection of more subtle motor deficits. Finally, the horizontal bars test is ideal for rapid screening of coordination and strength in the limbs (Mann and Chesselet, 2014). We employed all three of these tests, but still could not clearly document any distinct motor deficits in our mice after HPC, nothing that was statistically significant. Nevertheless, we were left with the distinct impression that our mice did have some subtle difficulties in performing all of these behavioral tests, for the first few days after HPC. Clearly though, this mild insult was not sufficient to permanently and dramatically affect the motor system and is one more reflection of the cerebellum's exquisite and powerful control over bodily movements (Foerde and Poldrack, 2010).

Regarding the reduced expression of EGFP we observed in several areas of the cerebellum of GFAPEGFP transgenic mice after HPC, we can be confident that this transgenic mouse line reports with a good level of fidelity the location of astrocytes and BG cells in the cerebellum (Nolte et al., 2001); and since EGFP is under the control of GFAP promoter, we can be certain that the intensity of fluorescence can properly be taken as evidence of changes in the levels of expression of GFAP, which forms the unique type of intermediate filaments that characterize such glial cells (Eng, 1985; Kobayashi et al., 1986; Sun and Jakobs, 2012). Furthermore, our approach of using LSFM for high-resolution imaging of clarified mice cerebella was clearly successful at showing that lobules of the cerebella respond with different intensity, which is likely related to the modular organization of the cerebellum.

The overall reduction in expression of EGFP we observed in transgenic GFAP-EGFP mice after HPC, paralleled by the reduced expression of GFAP and ALDH1L1 on Western blots, is hard to fit with previous work on other regions of the brain. Generally, it is held that ischemia activates astroglia, at least in striatum and cortex, and this activation induces tolerance to further ischemia, via activation of the purinergic $\mathrm{P} 2 \mathrm{X} 7$ receptor (Hirayama et al., 2015). Also, the increased expression of Iba1 and the morphological changes that we observed in microglial cells upon HPC contrasts with earlier observations made in striatum and cortex (Hirayama et al., 2015). Further investigations will be needed, to sort out the meaning of these differences.

Regarding the increased lengths of BG processes we observed after HPC (Fig. 6), it would be interesting to determine if this reflects an increase the number of glutamate receptors in contact with Purkinje neurons. If so, it might be one more indication that in the cerebellum, BG cells are dynamic and are deeply implicated in motor control (Saab et al., 2012). Additionally, it could parallel certain changes seen in other systems in response to HPC. For example, in the olfactory bulb, synaptic efficacy appears to be altered for a short period of time after HPC, possibly due to changes in synaptic ultrastructure (Liu et al., 2015). Also, HPC has been described as increasing glutamate receptors and nitric oxide in ways that may relate to its neuroprotective effects (Li et al., 2017). 

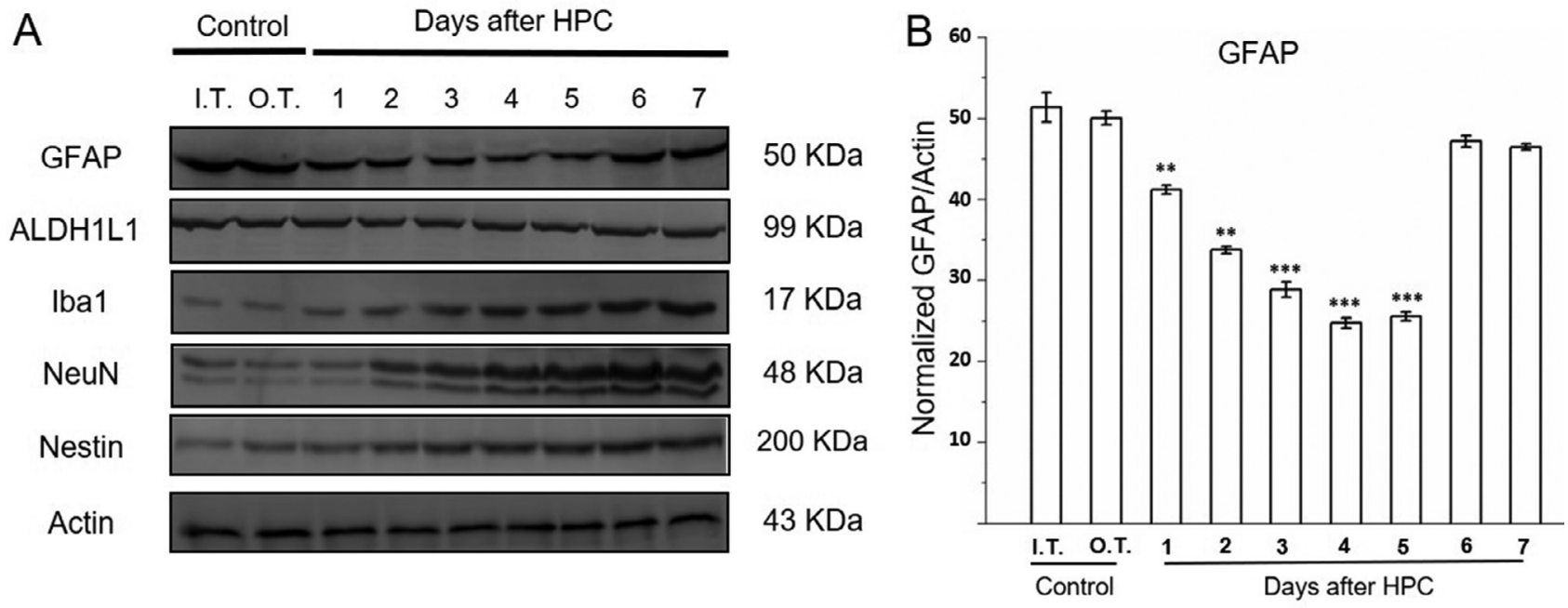

C

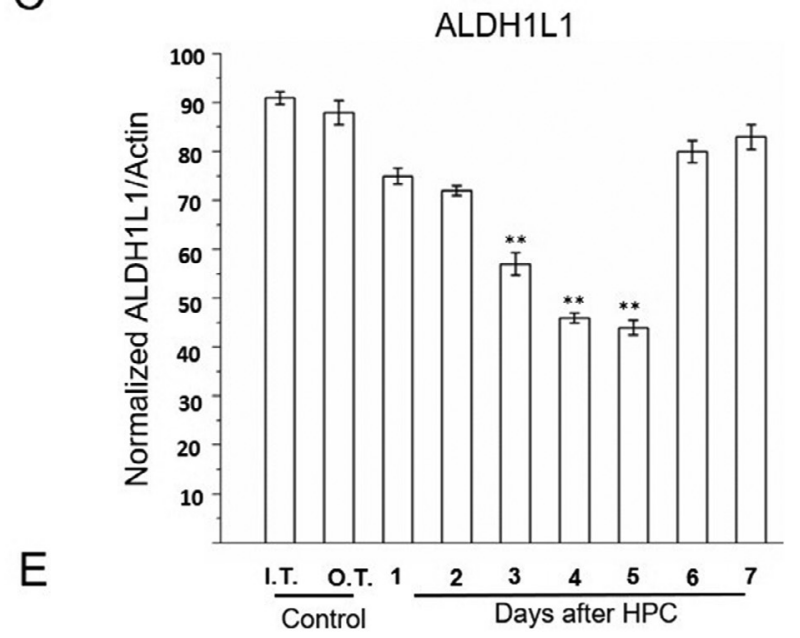

D
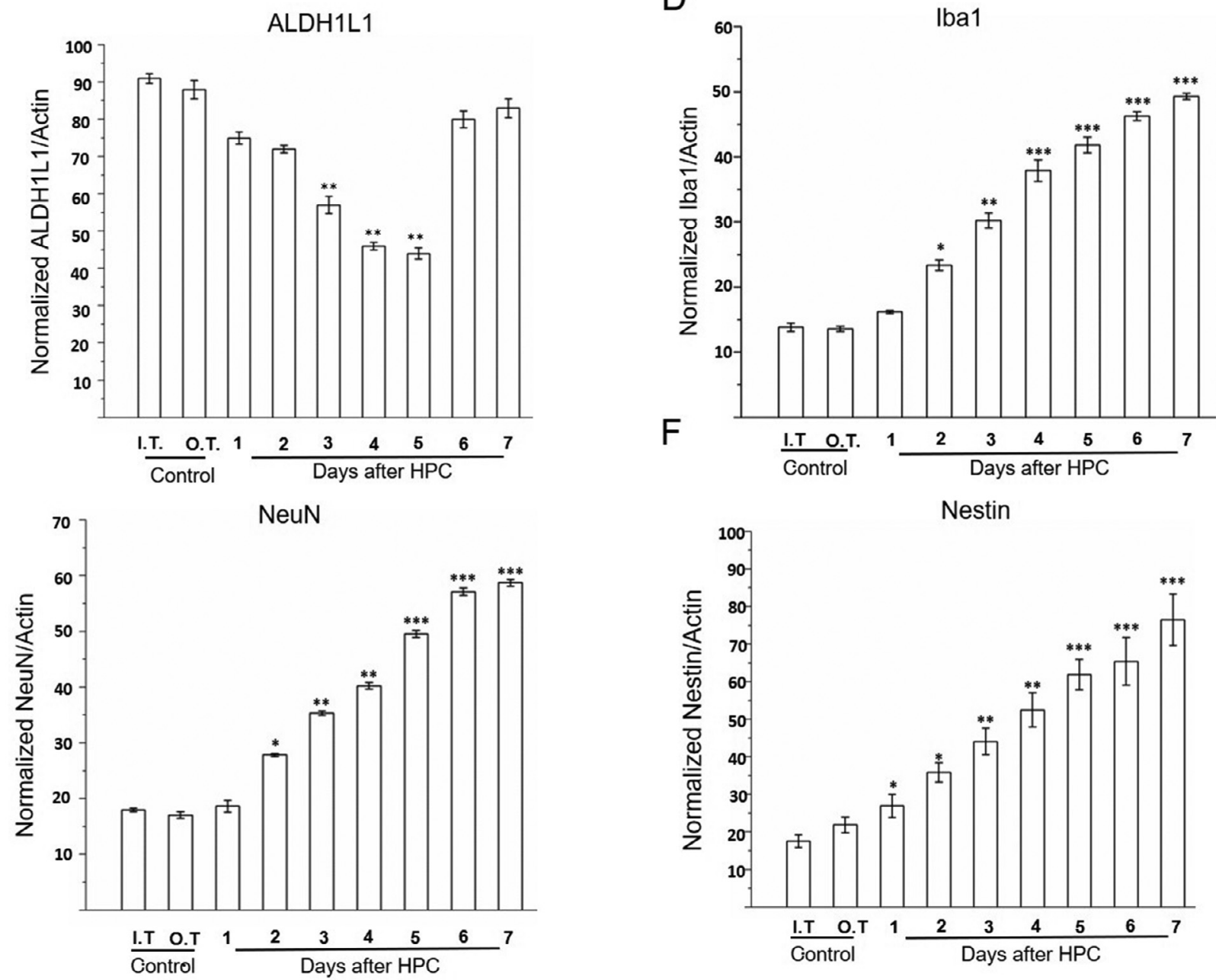

Fig. 7. Reduced expression of glial markers and increased expression in microglial, neuronal and stem cell markers after HPC. (A): Representative blots of proteins isolated from cerebella before and after HPC. B-F: Density revealed decreased relative expression of (B): GFAP and (C): ALDH1L1, and increased expression of (D): Iba1, (E): NeuN, and (F): nestin after HPC. Actin was used as internal control. HPC: Hypoxic preconditioning, I.T.: Inside a tube, O.T.: Outside a tube. Values are expressed as mean \pm SEM.

Regarding our observations of NeuN levels after HPC, we have the problem that we could not demonstrate any increase by immunofluorescence, yet we did observe some increase in NeuN expression by Western blotting. Regardless, the salient point is that we most certainly did not observe any increase in the number of $\mathrm{NeuN}+$ 


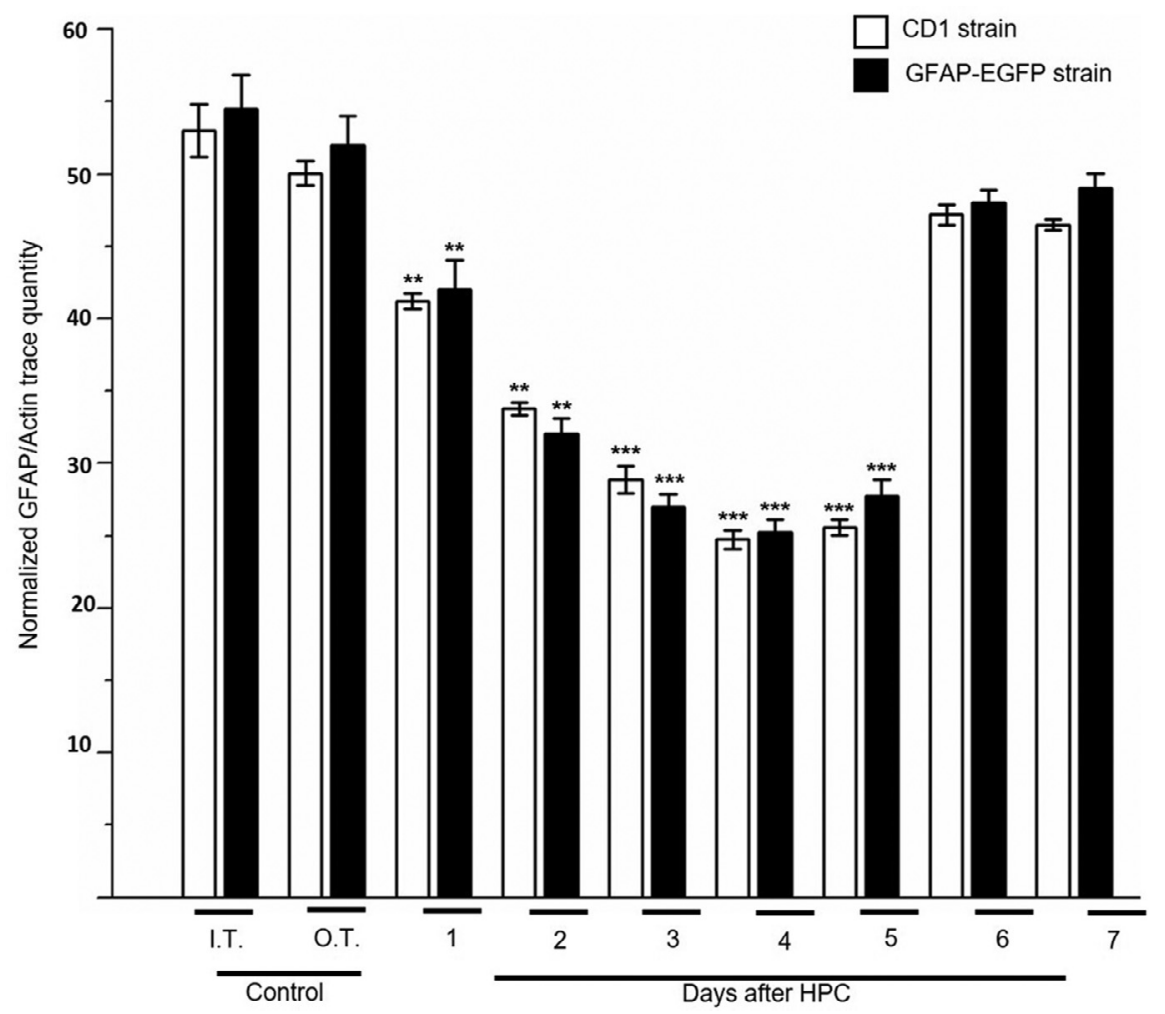

Fig. 8. Expression of GFAP after HPC in CD1 and GFAP-EGFP mice. A comparison between the level of GFAP expression was assessed by Western blot. After HPC there is no difference in the protein expression from day one until recovery at day seven between the strains (GFAP-EGFP vs CD1). Values are expressed as mean \pm SEM. Comparison of HPC with control groups showed significant differences. This supports the EGFP loss assessed by image analysis in coronal slices and en face preparation of transgenic GFAP-EGFP mice cerebella (Figs. 4 and 5).

cells in the cerebellum after HPC. NeuN label is normally found in granule neurons and a small population of other neurons in the lower molecular layer of the adult cerebellum (Weyer and Schilling, 2003). Finding no change here was a disappointment, since previous studies have shown that other sorts of preconditioning paradigms (like exercise for example, which also confers neuroprotective effects like the HPC used here), does appear to induce the differentiation of NeuN positive neurons in the cerebellum, apparently from Sox $2+$ and Nestin + cells that reside in the Purkinje cell and internal granule layers of the cerebellum, which start off lacking any neuronal and glial differentiation markers (Ahlfeld et al., 2017). Also, it has been suggested that NeuN expression levels can be indicative of the physiological status of a post mitotic neuron (Weyer and Schilling, 2003), so we would have been gratified if we could have demonstrated changes after HPC.

Regarding our observations on microglial cells in the cerebellum, it was interesting to find that Iba1 + cells in the SVZ looked differently than those in the molecular layer (e.g., appeared less "activated"), but were strikingly abundant in both areas (especially as compared to the density of Iba1 + cells in the Purkinje cell layer). Also relevant was our finding that microglial cells in the supra SVZ responded to HPC by increasing the size of their soma and the complexity of their processes, putting them more into their "activated" state (Noh et al., 2014; Sandvig et al., 2018). Microglia are thought to play a major role in the neuroinflammatory response in neurological diseases, potentiating neuronal recovery and in some cases regeneration (Noh et al., 2014; Sandvig et al., 2018). However, activation of microglia after HPC has not been reported in other brain areas, despite the fact that HPC protects these areas also (Chen et al., 2015). On the other hand, our results would suggest that in the cerebellum, and particularly in areas associated with $\mathrm{CSF}$, the response of microglia may be stronger than elsewhere in the brain, and may synergize with the changes we observed in BG cells and cells in the VMC, and thereby play an important role in protecting the cerebellum from insult.

Regarding the increases in nestin protein-levels we observed after HPC, our first thought is that it may reflect the onset of some sort of vascular remodeling, which could be expected to occur after hypoxic preconditioning (Calderone, 2018). We are currently evaluating this possibility by imaging blood vessels after Dil staining, and already have the impression that capillaries are indeed wider at their branches at 4 days post-HPC; however, this will be documented in subsequent reports.

Regarding the increase in BrdU incorporation we observed on the floor of the 4th ventricle (when we'd hoped to find it on the roof), the cells we found to respond to HPC might correspond to the tanycyte-like cells recently observed in this area, known as the E2 and E3 cells, which are currently thought to relay chemical information from the CSF to underlying neural circuits along the ventral midline (Mirzadeh et al., 2017).

This is the same sort of function that we proposed for the VMC (González-González et al., 2017), but not finding any cell proliferation in this area in response to HPC did not help our proposal very much. In contrast, stem and progenitor cells have been shown to proliferate in response to HPC in other species and in other ventricular zones, such as in the SVZ of the lateral ventricles (Ara \& De Montpellier, 2013; Blaise et al., 2009). All we can say is that the lack of BrdU we observed in the ependymal glial cells of the roof of the fourth ventricle is in line with previous reports, including our own (Grimaldi and Rossi, 2006; Su et al., 2014; Ahlfeld et al., 2017; González-Gon zález et al., 2017).

In summary, we here describe a broad range of structural and biochemical responses to HPC among cells on the roof and floor of the fourth ventricle, 
A

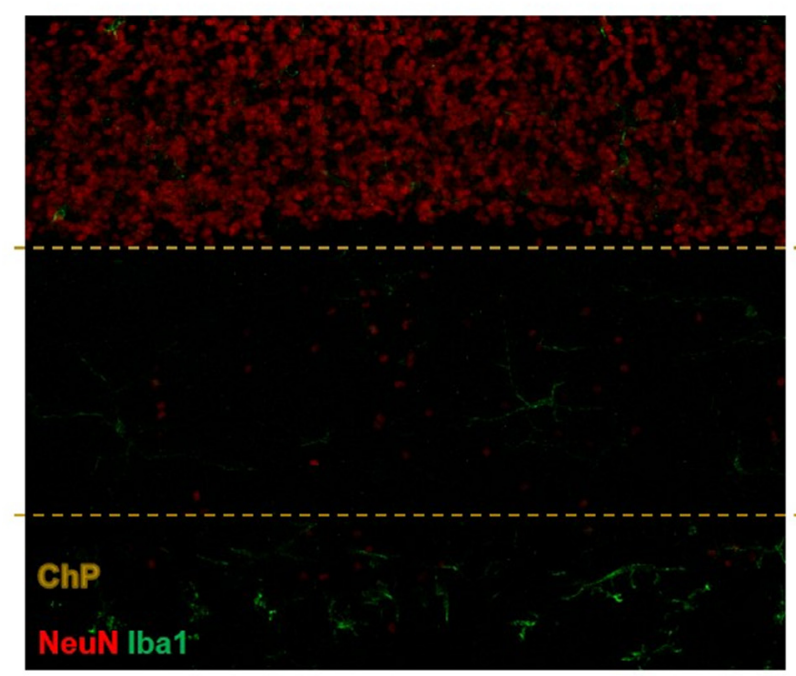

B

Number of NeuN-positive cells in the ML

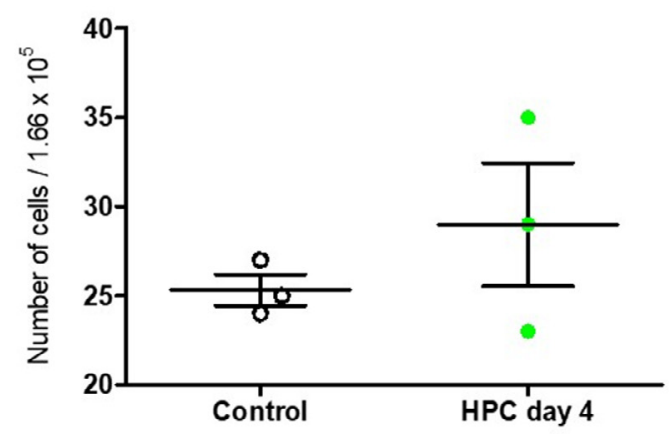

HPC day 4

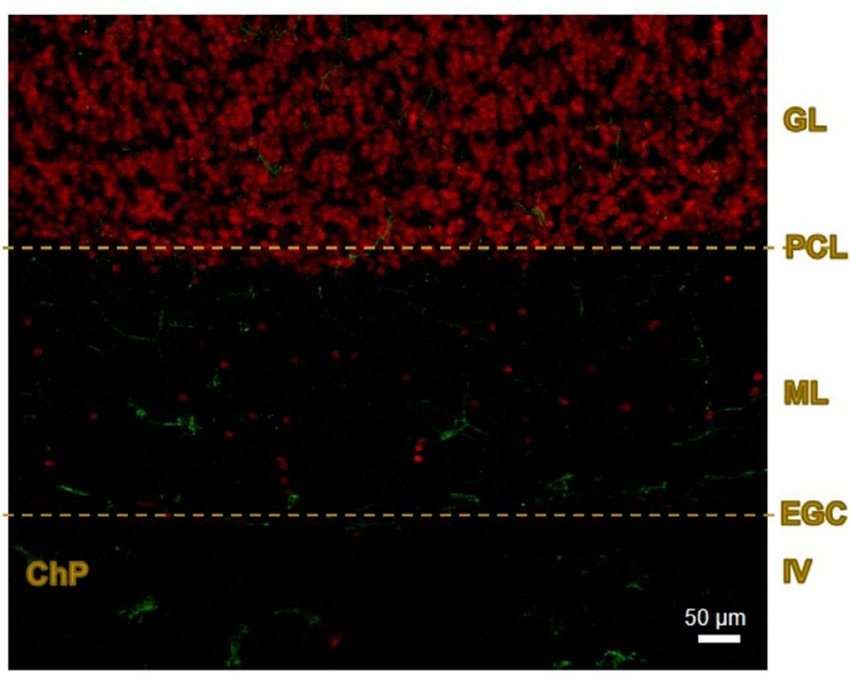

C

Integrated density of NeuN-positive cells in the ML

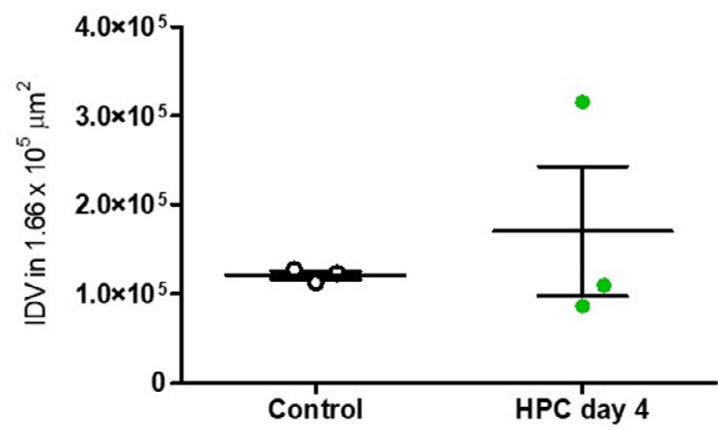

Fig. 9. Number of NeuN positive cells after the HPC. (A): Coronal slices from CD1 mice revealed no significative increase in the number of NeuN ${ }^{+}$ cells observed in the molecular layer as shown in (B). (C): shows no significative differences in the integrated density of NeuN ${ }^{+}$cells. Values are expressed as mean \pm SEM. HPC: Hypoxic preconditioning, GL: Granular layer, PCL: Purkinje cell layer, ML: Molecular layer, EGC: Ependymal glial cells. ChP: Choroid plexus, IDV: Integrated density values.

especially among the cells located in what we call the VMC, and especially involving the glial cells located therein. Broadly speaking, these observations support our original hypothesis that these cells are strategically placed to sense and respond to whatever changes may be induced in the CSF that bathes them. It will be fascinating to determine in future work, just what changes are occurring in the CSF, in response to stresses like HPC.

\section{ACKNOWLEDGMENTS}

Prof. H. Kettenmann (MDC-Berlin) and D. Reyes-Haro (INB-UNAM) for providing transgenic GFAP-EGFP mice; A.E. Espino and M. Ramírez, A. Castilla, M. García, D. Gasca, C. S. Flores and E. N. Hernández Ríos for technical assistance and Dr. R. Arellano's laboratory (INB-UNAM). Thanks to Prof. John Heuser for observations and editing the manuscript. This work was supported by Grant A1-S-7659 from CONACyT to AMT. MBG and GBGG were supported by CONACyT (Fellowships 330119 and 277694), MBG is a doctoral student from the Programa de Doctorado en Ciencias Biomédicas, Universidad Nacional Autónoma de México (UNAM), MBG was supported by a PAEP travel grant. RVD was supported by a postdoctoral fellowship from UNAM-DGAPA. We thank to $\mathrm{K}$. Engberg and $\mathrm{K}$. Deisseroth from Stanford University. EJG and PLA acknowledge financial support from the Spanish Ministry of Economy and Competitiveness (AEI/FEDER), through founded programs BIO2014-59614-JIN, RYC2015-17935 and FIS2016-80455-R (AEI/FEDER), European Union grant EU-H2020 713140; the "Severo Ochoa" Programme for Centres of Excellence in R\&D (SEV-2015-0522), Fundació Privada Cellex, Fundación Mig-Puig and the CERCA program and Laserlab-Europe (EU-H2020 654148). GBGG and AB acknowledge 
A

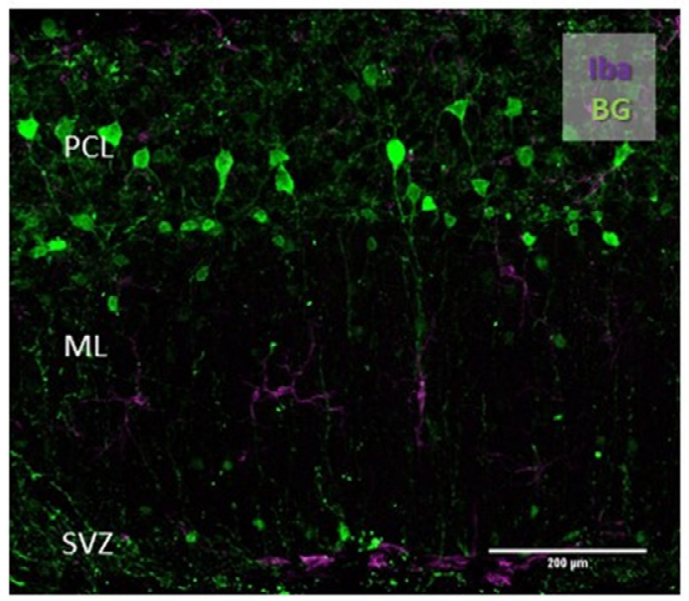

C
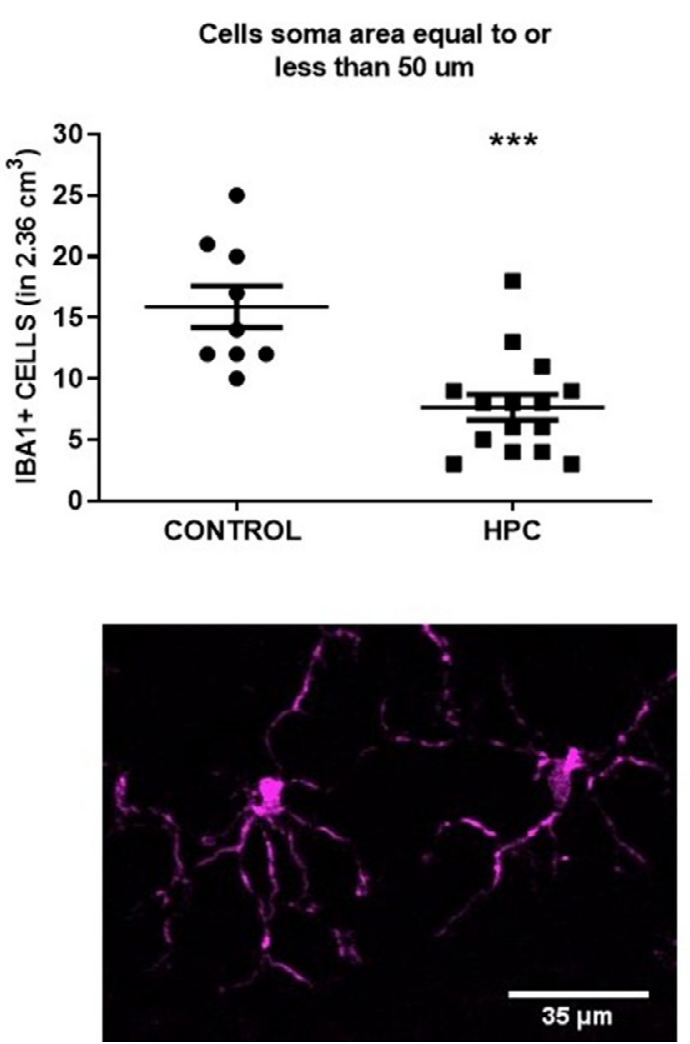

B

Total Iba1+ cells

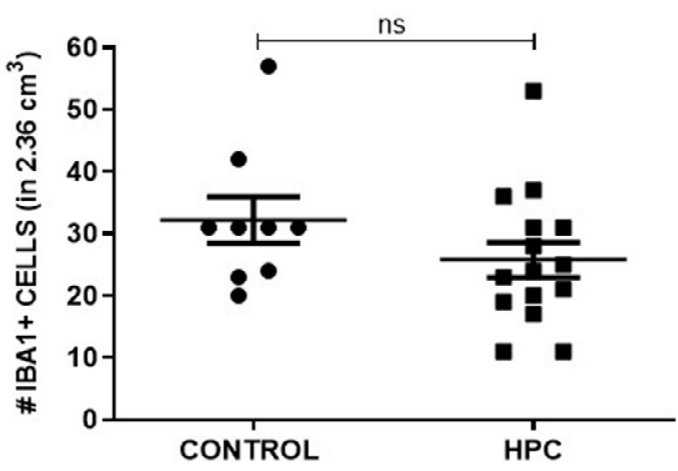

Cells soma area greather than 50 um
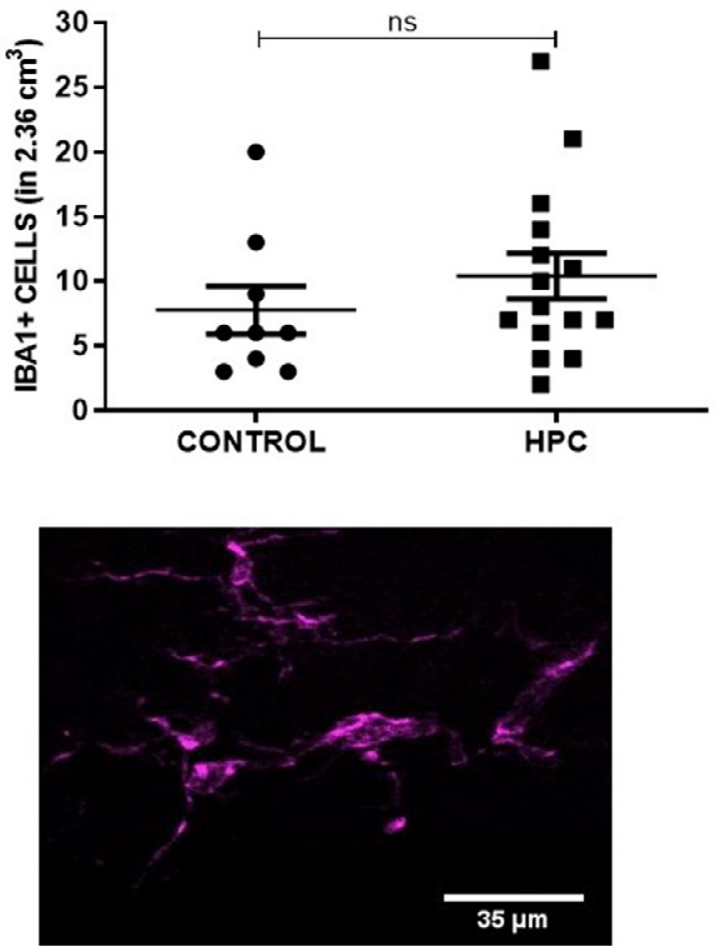

Fig. 10. Analysis of $\mathrm{Iba} 1^{+}$cells after HPC. Coronal slices from lobule I were analyzed by confocal microscopy after Iba1 immunodetection in GFAPEGFP and Pax2-GFP mice. (A): Sample image that shows Iba1 ${ }^{+}$cell distribution across cerebellar layers of lobule I from control mice. Note the preferential presence of $\mathrm{Iba} 1^{+}$cells in the SVZ. (B): Total Iba1 ${ }^{+}$cells along lobule I did not change 4 days after HPC. (C): The number of Iba ${ }^{+}$cells with area of the soma equal to or less than $50 \mu \mathrm{m}$ decreased in the supra SVZ 4 days after HPC; in contrast, (D): the number of cells with a soma larger than $50 \mu \mathrm{m}$ remained unaltered after HPC. C and D show sample images of $\mathrm{lba}^{+}{ }^{+}$cells to contrast the size of the somata. BG: Bergmann glia, PCL: Purkinje cell layer, ML: molecular layer, SVZ: Subventricular zone, HPC: Hypoxic preconditioning. Bar: in A: $200 \mu \mathrm{m}$ and in C, D: $35 \mu \mathrm{m}$.

financial support from the Italian Ministry of Higher Education and the University of Torino (Italy), under the auspices of I@UNITO - Visiting Scientists project, 2017 edition. J. G. Norris kindly edited the manuscript. AMT dedicated this paper to Prof. Ricardo Miledi (19272017), mentor and friend. 


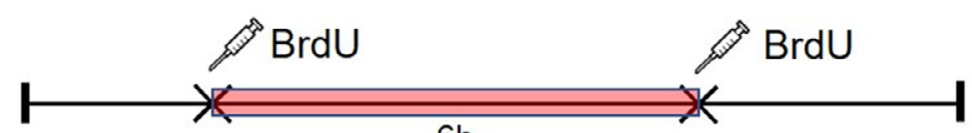

Daily dose

$6 \mathrm{~h}$

B

CONTROL

HPC day 4

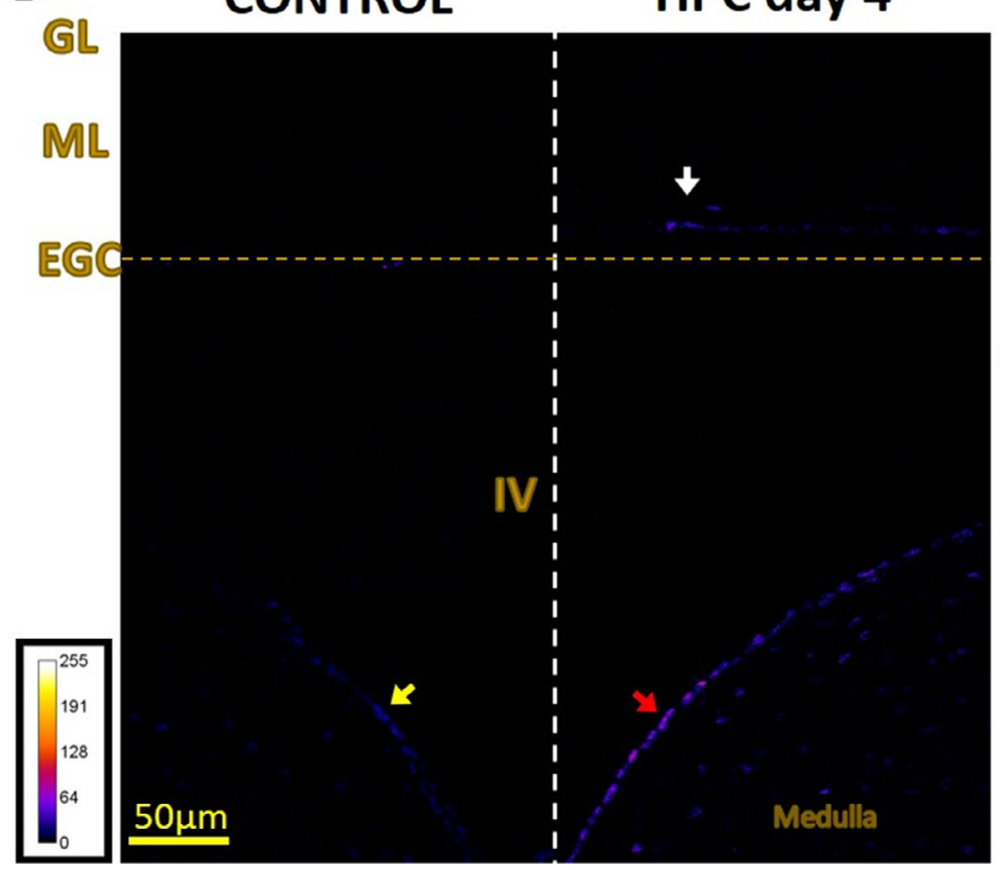

C

Fig. 11. Limited incorporation of BrdU was detected at the roof of the fourth ventricle after HPC. (A): Two BrdU injections (50 mg/kg) with a $6 \mathrm{~h}$ interval were intraperitoneally administered daily for 5 days after HPC and prior to euthanizing. (B): Control group showed some incorporation of $\mathrm{BrdU}$ in cells of the floor of the fourth ventricle corresponding to the medulla (yellow arrow), which became more evident 4 days after HPC (red arrow). This contrasted with the cerebellum, where BrdU was scarcely detected in controls but detected 4 days after HPC along the EGC (white arrow). (C): A statistical significative difference was observed in the integrated density values when comparing the BrdU incorporation in the roof of the fourth ventricle. HPC: Hypoxic preconditioning, GL: Granular layer, ML: Molecular layer, EGC: Ependymal glial cells, IV: Fourth ventricle, IDV: Integrated density values.

\section{DECLARATIONS OF INTEREST}

None.

\section{REFERENCES}

Ahlfeld J, Filser S, Schmidt F, Wefers AK, Merk DJ, Glaß R, Herms J, Schüller U (2017) Neurogenesis from Sox2 expressing cells in the adult cerebellar cortex. Sci Rep 7:6137. Available at: http://www. ncbi.nlm.nih.gov/pubmed/28733588 [Accessed January 13, 2019].

Ara J, De montpellier S (2013) Hypoxic-preconditioning enhances the regenerative capacity of neural stem/progenitors in subventricular zone of newborn piglet brain. Stem Cell Res 11:669-686. Available at: https://www.sciencedirect.com/science/article/pii/ S1873506113000457?via\%3Dihub [Accessed June 4, 2018].

Benitez SG, Castro AE, Patterson SI, Muñoz EM, Seltzer AM (2014) Hypoxic preconditioning differentially affects GABAergic and glutamatergic neuronal cells in the injured cerebellum of the neonatal rat. PLoS One 9.

Blaise SA, Nédélec E, Alberto J-M, Schroeder H, Audonnet S, Bossenmeyer-Pourié C, Guéant J-L, Daval J-L (2009) Short hypoxia could attenuate the adverse effects of hyperhomocysteinemia on the developing rat brain by inducing neurogenesis. Exp Neurol 216:231-238. Available at: https://
www.sciencedirect.com/science/article/pii/S0014488608004676 [Accessed June 4, 2018].

Bonfanti L (2013) The (real) neurogenic/gliogenic potential of the postnatal and adult brain parenchyma. ISRN Neurosci 2013:354136. Available at: http://dx.doi.org/10.1155/2013/ 354136 [Accessed March 6, 2018].

Bradford MM (1976) A rapid and sensitive method for the quantitation of microgram quantities of protein utilizing the principle of proteindye binding. Anal Biochem 72:248-254. Available at: https:// www.sciencedirect.com/science/article/pii/0003269776905273? via\%3Dihub [Accessed January 20, 2019].

Brooks SP, Dunnett SB (2009) Tests to assess motor phenotype in mice: a user's guide. Nat Rev Neurosci 10:519-529.

Calderone A (2018) The biological role of Nestin(+)-cells in physiological and pathological cardiovascular remodeling. Front Cell Dev Biol 6:15. Available at: http://journal.frontiersin. org/article/10.3389/fcell.2018.00015/full [Accessed April 23, 2019].

Cerrato V, Mercurio S, Leto K, Fucà E, Hoxha E, Bottes S, Pagin M, Milanese M, Ngan CY, Concina G, Ottolenghi S, Wei CL, Bonanno G, Pavesi G, Tempia F, Buffo A, Nicolis SK (2018) Sox2 conditional mutation in mouse causes ataxic symptoms, cerebellar vermis hypoplasia, and postnatal defects of Bergmann glia. Glia 66:1929-1946.

Chen C-Y, Sun W-Z, Kang K-H, Chou H-C, Tsao P-N, Hsieh W-S, Fu W-M (2015) Hypoxic preconditioning suppresses glial activation and neuroinflammation in neonatal brain insults. Mediators 
Inflamm 2015:632592. Available at: http://www.ncbi.nlm.nih.gov/ pubmed/26273140 [Accessed May 10, 2018].

Cipolla MJ (2009) The cerebral circulation. Morgan \& Claypool Life Sciences. Available at: http://www.ncbi.nlm.nih.gov/pubmed/ 21452434 [Accessed June 4, 2018].

Davis BM, Salinas-Navarro M, Cordeiro MF, Moons L, De Groef L (2017) Characterizing microglia activation: a spatial statistics approach to maximize information extraction. Sci Rep.

De Zeeuw Cl, Hoogland TM (2015) Reappraisal of Bergmann glial cells as modulators of cerebellar circuit function. Front Cell Neurosci 9:246. Available at: http://journal.frontiersin.org/ Article/10.3389/fncel.2015.00246/abstract [Accessed April 11, 2018].

Deacon RMJ (2013) Measuring motor coordination in mice. J Vis Exp Available. Available at: http://www.jove.com/video/2609/ measuring-motor-coordination-in-mice.

Del MR (1995) The ependyma: a protective barrier between brain and cerebrospinal fluid. Glia 14(1). Available at: https://onlinelibrary. wiley.com/doi/pdf/10.1002/glia.440140102 [Accessed June 4, 2018].

Diaz-Cintra S, Cintra L, Kemper T, Resnick O, Morgane PJ (1981) Nucleus raphe dorsalis: A morphometric golgi study in rats of three age groups. Brain Res 207:1-16. Available at: https:// linkinghub.elsevier.com/retrieve/pii/0006899381906752 [Accessed June 7, 2019].

Emerson MR, Nelson SR, Samson FE, Pazdernik TL (1999) A global hypoxia preconditioning model: neuroprotection against seizureinduced specific gravity changes (edema) and brain damage in rats. Brain Res Brain Res Protoc 4:360-366. Available at: http:// www.ncbi.nlm.nih.gov/pubmed/10592346 [Accessed May 28, 2019].

Eng LF (1985) Glial fibrillary acidic protein (GFAP): the major protein of glial intermediate filaments in differentiated astrocytes. J Neuroimmunol.

Feliciano DM, Bordey A, Bonfanti L (2015) Noncanonical sites of adult neurogenesis in the mammalian brain. Cold Spring Harb Perspect Biol 7:a018846. Available at: http://www.ncbi.nlm. nih.gov/pubmed/26384869 [Accessed April 20, 2018].

Foerde K, Poldrack RA (2010) Procedural learning in humans. Encyclopedia of neuroscience, 2010.

Gage GJ, Kipke DR, Shain W (2012) Whole animal perfusion fixation for rodents. J Vis Exp. Available at: http://www.jove.com/video/ 3564/whole-animal-perfusion-fixation-for-rodents.

Gidday JM, Perez-Pinzon MA, Zhang JH (2013) Innate tolerance in the CNS: Translational neuroprotection by pre- and postconditioning.

González-González MA, Gómez-González GB, Becerra-González M, Martínez-Torres A (2017) Identification of novel cellular clusters define a specialized area in the cerebellar periventricular zone. Sci Rep 7.

González-González MA, Ostos-Valverde A, Becerra-Hernández A, Sánchez-Castillo H, Martínez-Torres A (2015) The effect of carmustine on Bergmann cells of the cerebellum. Neurosci Lett 595:18-24. Available at: https://www.sciencedirect.com/science/ article/pii/S0304394015002700?via\%3Dihub\#! [Accessed January 20, 2019].

Grimaldi P, Rossi F (2006) Lack of neurogenesis in the adult rat cerebellum after Purkinje cell degeneration and growth factor infusion. Eur J Neurosci 23:2657-2668. Available at: http://doi. wiley.com/10.1111/j.1460-9568.2006.04803.x [Accessed January 14, 2019].

Hanke S, Reichenbach A (1987) Quantitative-morphometric aspects of bergmann glial (Golgi epithelial) cell development in rats - a golgi study. Anat Embryol (Berl) 177:183-188.

Hibi M, Matsuda K, Takeuchi M, Shimizu T, Murakami Y (2017) Evolutionary mechanisms that generate morphology and neuralcircuit diversity of the cerebellum. Dev Growth Differ 59:228-243. Available at: http://doi.wiley.com/10.1111/dgd.12349 [Accessed January 20, 2019].

Hirayama Y, Ikeda-Matsuo Y, Notomi S, Enaida H, Kinouchi H, Koizumi S (2015) Astrocyte-mediated ischemic tolerance. J
Neurosci 35:3794-3805. Available at: http://www.ncbi.nlm. nih.gov/pubmed/25740510 [Accessed June 4, 2018].

Hoogland TM, De Gruijl JR, Witter L, Canto CB, De Zeeuw Cl (2015) Role of synchronous activation of cerebellar Purkinje cell ensembles in multi-joint movement control. Curr Biol 25:1157-1165. Available at: http://www.ncbi.nlm.nih.gov/ pubmed/25843032 [Accessed January 20, 2019].

Horie N, So K, Moriya T, Kitagawa N, Tsutsumi K, Nagata I, Shinohara K (2008) Effects of oxygen concentration on the proliferation and differentiation of mouse neural stem cells in vitro. Cell Mol Neurobiol 28:833-845.

Kim H-Y (2015) Statistical notes for clinical researchers: post-hoc multiple comparisons. Restor Dent Endod 40:172-176. Available at: http://www.ncbi.nlm.nih.gov/pubmed/25984481 [Accessed May 22, 2019].

Kobayashi S, Chiu FC, Katayama M, Sacchi RS, Suzuki K, Suzuki K (1986) Expression of glial fibrillary acidic protein in the CNS and PNS of murine globoid cell leukodystrophy, the twitcher. Am J Pathol 125:227-243. Available at: http://www.ncbi.nlm.nih.gov/ pubmed/3538889 [Accessed January 20, 2019].

Kriegstein A, Alvarez-Buylla A (2009) The glial nature of embryonic and adult neural stem cells. Annu Rev Neurosci 32:149-184. Available at: http://www.annualreviews.org/doi/10.1146/annurev. neuro.051508.135600.

Lang $\mathrm{H}$, Xing $\mathrm{Y}$, Brown LN, Samuvel DJ, Panganiban CH, Havens LT, Balasubramanian S, Wegner M, Krug EL, Barth JL (2015) Neural stem/progenitor cell properties of glial cells in the adult mouse auditory nerve. Sci Rep 5. Available at: https://www.nature.com/ articles/srep13383.

Li S, Hafeez A, Noorulla F, Geng X, Shao G, Ren C, Lu G, Zhao H, Ding $Y$, Ji X (2017) Preconditioning in neuroprotection: from hypoxia to ischemia. Prog Neurobiol.

Liu C, Peng Z, Zhang N, Yu L, Han S, Li D, Li J (2012) Identification of differentially expressed microRNAs and their PKC-isoform specific gene network prediction during hypoxic pre-conditioning and focal cerebral ischemia of mice. J Neurochem 120:830-841.

Liu Y, Sun Z, Sun S, Duan Y, Shi J, Qi Z, Meng R, Sun Y, Zeng X, Chui D, Ji X (2015) Effects of hypoxic preconditioning on synaptic ultrastructure in mice. Synapse.

López-Aguilera F, Plateo-Pignatari MG, Biaggio V, Ayala C, Seltzer AM (2012) Hypoxic preconditioning induces an AT2-R/VEGFR-2 (Flk-1) interaction in the neonatal brain microvasculature for neuroprotection. Neuroscience 216:1-9.

Mandalos NP, Karampelas L, Saridaki M, McKay RDG, Cohen ML, Remboutsika E (2018) A role for Sox2 in the adult cerebellum. J Stem Cell Res Ther 8. Available at: http://www.ncbi.nlm.nih.gov/ pubmed/30568848 [Accessed January 13, 2019].

Mann A, Chesselet MF (2014) Techniques for Motor Assessment in Rodents. Movement disorders: genetics and models: second edition, 2014.

Mirzadeh Z, Kusne Y, Duran-Moreno M, Cabrales E, Gil-Perotin S, Ortiz C, Chen B, Garcia-Verdugo JM, Sanai N, Alvarez-Buylla A (2017) Bi- and uniciliated ependymal cells define continuous floorplate-derived tanycytic territories. Nat Commun 8.

National Research Council (U.S.), Committee for the Update of the Guide for the Care and Use of Laboratory Animals, Institute for Laboratory Animal Research (U.S.) (2011) Guide for the care and use of laboratory animals. National Academies Press.

Noh H, Jeon J, Seo H (2014) Systemic injection of LPS induces region-specific neuroinflammation and mitochondrial dysfunction in normal mouse brain. Neurochem Int 69:35-40. Available at: https://www.sciencedirect.com/science/article/pii/ S0197018614000382?via\%3Dihub [Accessed June 4, 2018].

Nolte C, Matyash M, Pivneva T, Schipke CG, Ohlemeyer C, Hanisch UK, Kirchhoff F, Kettenmann H (2001) GFAP promoter-controlled EGFP-expressing transgenic mice: a tool to visualize astrocytes and astrogliosis in living brain tissue. Glia 33:72-86.

Olarte OE, Andilla J, Gualda EJ, Loza-Alvarez P (2018) Light-sheet microscopy: a tutorial. Adv Opt Photonics 10:111. Available at: https://www.osapublishing.org/abstract.cfm?URI = aop-10-1-111 [Accessed June 14, 2018]. 
Parmigiani $\mathrm{E}$, Leto $\mathrm{K}$, Rolando $\mathrm{C}$, Figueres-Oñate $\mathrm{M}$, LópezMascaraque L, Buffo A, Rossi F (2015) Heterogeneity and bipotency of astroglial-like cerebellar progenitors along the interneuron and glial lineages. J Neurosci 35:7388-7402. Available at: http://www.ncbi.nlm.nih.gov/pubmed/25972168 [Accessed May 10, 2018].

Ponti G, Peretto P, Bonfanti L (2008) Genesis of neuronal and glial progenitors in the cerebellar cortex of peripuberal and adult rabbits. PLoS One 3:e2366. Available at: http://www.ncbi.nlm. nih.gov/pubmed/18523645 [Accessed April 20, 2018].

Reyes-Haro D, González-González MA, Pétriz A, Rosas-Arellano A, Kettenmann H, Miledi R, Martínez-Torres A (2013) $\gamma$ Aminobutyric acid- $\rho$ expression in ependymal glial cells of the mouse cerebellum. J Neurosci Res 91:527-534. Available at: http://doi.wiley.com/10.1002/jnr.23183 [Accessed April 10, 2018].

Rosas-Arellano A, Ochoa-de la Paz LD, Miledi R, Martínez-Torres A (2007) Brain distribution and molecular cloning of the bovine GABA $\rho 1$ receptor. Neurosci Res 57:347-353. Available at: http:// www.ncbi.nlm.nih.gov/entrez/query.fcgi?cmd $=$ Retrieve\&db $=\mathrm{Pu}$ bMed\&dopt $=$ Citation\&list uids $=17188384$.

Rybnikova E, Samoilov M (2015) Current insights into the molecular mechanisms of hypoxic pre- and postconditioning using hypobaric hypoxia. Front Neurosci 9.

Saab AS, Neumeyer A, Jahn HM, Cupido A, Šimek AAM, Boele HJ, Scheller A, Le Meur K, Götz M, Monyer H, Sprengel R, Rubio ME, Deitmer JW, De Zeeuw Cl, Kirchhoff F (2012) Bergmann glial AMPA receptors are required for fine motor coordination. Science (80-).

Sandvig I, Augestad IL, Håberg AK, Sandvig A (2018) Neuroplasticity in stroke recovery. The role of microglia in engaging and modifying synapses and networks. Eur J Neurosci. Available at: http://doi.wiley.com/10.1111/ejn.13959 [Accessed June 4, 2018].

Santilli G, Lamorte G, Carlessi L, Ferrari D, Rota Nodari L, Binda E, Delia D, Vescovi AL, De Filippis L (2010) Mild hypoxia enhances proliferation and multipotency of human neural stem cells Najbauer J, ed.. PLoS One 5:e8575. Available at: http://dx.plos. org/10.1371/journal.pone.0008575.

Shiga T, Ichikawa M, Hirata Y (1983) A Golgi study of Bergmann glial cells in developing rat cerebellum. Anat Embryol (Berl) 167:191-201.
Stefaniuk M, Gualda EJ, Pawlowska M, Legutko D, Matryba P, Koza P, Konopka W, Owczarek D, Wawrzyniak M, Loza-Alvarez P, Kaczmarek L (2016) Light-sheet microscopy imaging of a whole cleared rat brain with Thy1-GFP transgene. Sci Rep 6:28209. Available at: http://www.nature.com/articles/srep28209 [Accessed January 20, 2019].

Su X, Guan W, Yu Y-C, Fu Y (2014) Cerebellar st em cells do not produce neurons and astrocytes in adult mouse. Biochem Biophys Res Commun 450:378-383. Available at: https:// www.sciencedirect.com/science/article/pii/S0006291X14010201? via\%3Dihub [Accessed April 20, 2018].

Sun D, Jakobs TC (2012) Structural remodeling of astrocytes in the injured CNS. Neuroscientist 18:567-588. Available at: http://www. ncbi.nlm.nih.gov/pubmed/21982954 [Accessed January 20, 2019].

Voogd J, Glickstein M (1998) The anatomy of the cerebellum. Trends Neurosci 21:370-375. Available at: http://www.ncbi.nlm.nih.gov/ pubmed/9735944 [Accessed April 9, 2018].

Weyer A, Schilling K (2003) Developmental and cell type-specific expression of the neuronal marker $\mathrm{NeuN}$ in the murine cerebellum. J Neurosci Res.

Witter L, De Zeeuw Cl (2015) Regional functionality of the cerebellum. Curr Opin Neurobiol 33:150-155. Available at: https://www.sciencedirect.com/science/article/pii/ S0959438815000720?via\%3Dihub [Accessed January 20, 2019].

Zhang N, Yin Y, Han S, Jiang J, Yang W, Bu X, Li J (2011) Hypoxic preconditioning induced neuroprotection against cerebral ischemic injuries and its $\mathrm{CPKC} \gamma$-mediated molecular mechanism. Neurochem Int 58:684-692.

Zhang Y-B, Guo Z-D, Li M-Y, Li S-J, Niu J-Z, Yang M-F, Ji X-M, Lv GW (2015) Cerebrospinal fluid from rats given hypoxic preconditioning protects neurons from oxygen-glucose deprivation-induced injury. Neural Regen Res 10:1471-1476. Available at: http://www.ncbi.nlm.nih.gov/pubmed/26604909 [Accessed January 20, 2019].

Zhu LL, Wu LY, Yew DT, Fan M (2005) Effects of hypoxia on the proliferation and differentiation of NSCs. In: Molecular neurobiology. Humana Press. p. 231-242. 